\title{
Plasticity in the Barrel Cortex of the Adult Mouse: Effects of Chronic Stimulation upon Deoxyglucose Uptake in the Behaving Animal
}

\author{
E. Welker, S. B. Rao, J. Dörfl, P. Melzer, ${ }^{a}$ and H. Van der Loos \\ Institute of Anatomy, University of Lausanne, 1005 Lausanne, Switzerland
}

\begin{abstract}
We investigated experience-dependent regulation of neuronal activity in the whisker-to-barrel pathway of the adult mouse using the autoradiographic deoxyglucose (DG) method. Animals were placed in the Lausanne whisker stimulator, and three of their whisker follicles were passively stimulated for a period of 1, 2, or $4 \mathrm{~d}$. After this period, mice received a dose of DG and were placed in a cage containing a pile of wooden sticks. Mice that underwent the same procedure except the passive stimulation served as controls. Patterns of stimulus-dependent DG uptake were studied in the somatosensory cortex and in the trigeminal sensory brainstem complex. DG uptake in the barrels corresponding to the passively stimulated whiskers was lower than in controls. This decrease was present throughout the radial extent of a barrel column and was observed in all passively stimulated animals. Quantitative analysis confirmed these observations and, furthermore, showed a statistically significant decrease in DG uptake in barrels neighboring the passively stimulated ones. In half of the animals, the brainstem nuclei showed a decreased DG uptake in the representation of the passively stimulated whiskers, whereas in the other animals the pattern of DG uptake was as in controls. We propose that the signs of cortical plasticity are due to a mechanism that operates in layer IV and functions as a gate for peripheral sensory activity to enter cortical circuitry.
\end{abstract}

The configuration of cortical maps of the peripheral sensory sheet in the adult brain is under the continuous influence of peripheral sensory activity. Arguments for this relationship between peripheral and central events in the adult organism at first came from observations in the primary somatosensory cortex (SI) of the monkey. Merzenich et al. (1983a,b) showed that after partial denervation of the hand, in the part of the map in SI corresponding to the denervated periphery, physiological responses appear upon stimulation of skin areas neighboring the deprived zone. Other studies have shown similar cortical alterations following the peripheral manipulation in several mammalian species (e.g., rat; Wall and Cusick, 1984; raccoon: Turnbull and Rasmusson, 1990; flying fox: Calford and Tweedale, 1988). With respect to the mechanisms that may underlie these

\footnotetext{
Received Mar. 20, 1991; revised Aug. 16, 1991; accepted Aug. 21, 1991.

We thank S. Daldoss for help with photography, and R. Kraftsik and N. Jeanprêtre for help with data processing. This work was supported by Swiss National Science Foundation Grant 3100.009468.

Correspondence should be addressed to E. Welker, Institute of Anatomy, University of Lausanne, Rue du Bugnon 9, 1005 Lausanne, Switzerland.

a Present address: Laboratory of Cerebral Metabolism, National Institute of Mental Health, Building 36, Room 1 A05, Bethesda, MD 20892, USA.

Copyright @ 1992 Society for Neuroscience 0270-6474/92/120153-18\$05.00/0
}

events, it was proposed that the inhibitory neurotransmitter GABA could play a role (Dykes et al., 1984). In the visual pathway, Hendry and Jones $(1986,1988)$ demonstrated a decrease in the level of GABA immunohistochemistry in the primary visual cortex after monocular deprivation in the adult monkey, which returned to normal values upon restoration of sensory activity. In agreement with the findings by these authors, modifications in levels of glutamic acid decarboxylase (GAD; the GABA-synthesizing enzyme) have been demonstrated to occur in SI after partial denervation of the whiskerpad of the mouse (Welker et al., 1989a) or of the hindpaw of thc rat (Warren et al., 1989).

In contrast to these paradigms in which stimulus-dependent regulation of aspects of cortical function were studied after sensory deprivation, we recently analyzed the cortical effects of chronic stimulation of a set of whiskers in the adult mouse using the Lausanne whisker stimulator. Four days of continuous whisker stimulation resulted in an increase in GAD immunoreactivity in the barrels corresponding to the stimulated whiskers (Welker et al., 1989b). The increase of GAD immunoreactivity was due to an increase in the numerical density of immunoreactive boutons, as well as to an increase of their staining intensity. Upon arrest of stimulation, the immunoreactivity gradually returned to normal levels over a period of $4 \mathrm{~d}$. Since immunoreactive puncta were found to be presynaptic to both GABA-positive and GABA-negative cell bodies, we could only speculate about the effect of a temporary increase in GABAergic innervation on sensory processing in the behaving animal.

The aim of the present study was to investigate the effects of chronic whisker stimulation on functional activity in the barrel cortex (that part of the somatosensory cortex that contains, in layer IV, barrels that represent the large, posterior vibrissal follicles) of the freely moving and whisking mouse using the autoradiographic deoxyglucose (DG) method (Sokoloff et al., 1977). After a period of prolonged passive stimulation of a restricted number of whiskers (during 1, 2, or $4 \mathrm{~d}$ ), the mice received an injection of radioactive DG and were placed in a stimulus-rich (i.e., object-filled) cage, which they actively explored for $45 \mathrm{~min}$. The animals were then processed for autoradiography.

The rationale of the experimental design is as follows. In the mouse, mystacial whisker follicles are arranged in five horizontal rows (Fig. 1). We have shown that the level of DG uptake in the barrel cortex depends on the number of whiskers stimulated within a row: DG uptake in a barrel corresponding to a stimulated follicle is higher when more than one (adjacent) whiskers of the same row are stimulated (Melzer et al., 1985a). Based on this observation, we designed the present experiment such that just prior to the moment of DG injection, that is, after the period of prolonged passive stimulation, the number and distribution 

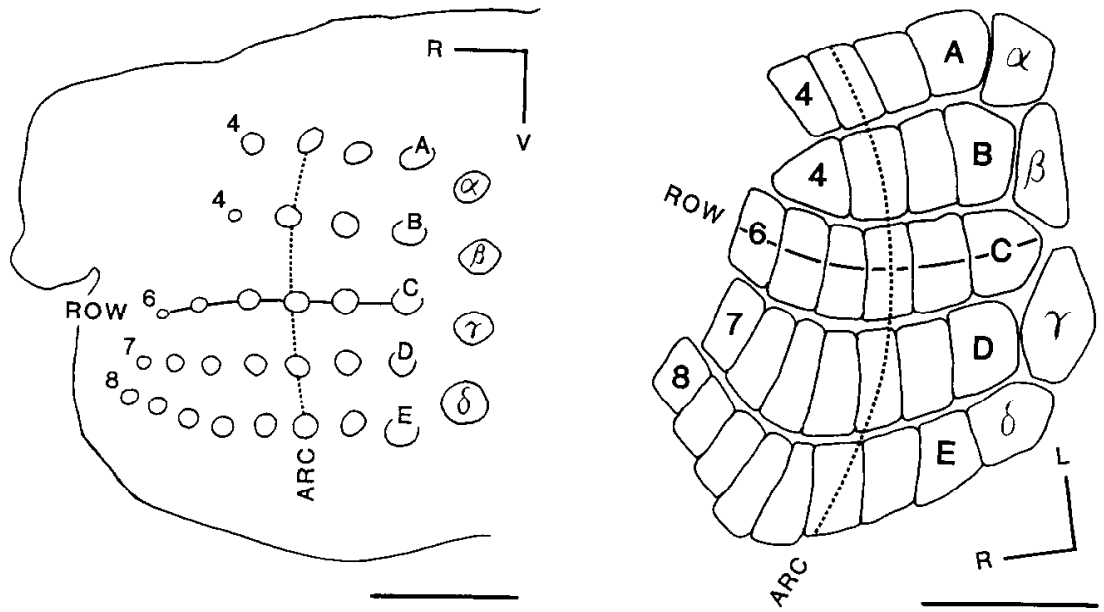

Figure 1. Illustrations indicating the terminology used in the description of the whisker-to-barrel pathway. Left, Drawing from a section of a left whiskerpad that was cut tangentially to the skin surface; circular profiles represent the whisker follicles; letters indicate the horizontal rows (solid line connects follicles of row $\mathrm{C}$ ); within a row whiskers are numbered, starting from caudal side; the broken line connects the third follicles of each row, together forming an $\operatorname{arc}$; straddling elements at caudal border of the whiskerpad are denoted with greek letters. Right, Drawing of a right barrel field reconstructed from sections taken tangential to the pial surface, through layer IV of the somatosensory cortex; individual barrels are outlined; orientation, lettering, and numbering is such that topological relationship with the distribution of whisker follicles is readily seen. Orientation: $R$, rostral; $V$, ventral; $L$, lateral. Scale bars: left, $2 \mathrm{~mm}$; right, $500 \mu \mathrm{m}$.

of whiskers in all five rows were made identical; this was determined by recording which of the passively stimulated whiskers were still present at the moment of DG injection. In this manner, we could compare DG uptake of the passively stimulatcd barrcls with those of the neighboring barrels within the same animal.

We observed a decrease in DG uptake in the harrel columns corresponding to the passively stimulated whisker follicles (a barrel column is a barrel in layer IV plus the tissue above and below it). Half of the animals showed similar modifications in the whisker representation in two of the trigeminal subnuclei in the brainstem.

Preliminary data have been reported in abstract form (Rao et al., 1989).

\section{Materials and Methods}

Twenty-five adult mice of the NOR strain derived from ICR stock (mice characterized by a standard pattern of mystacial vibrissae; Van der Loos et al., 1986) of both sexes were used in this study.

Passive stimulation. Mice of the experimental group $(n=18$; Table 1) were anesthetized with Nembutal (sodium pentobarbital, $60 \mathrm{mg} / \mathrm{kg}$, i.p.), and metal pieces ( $1.5 \mathrm{~mm}$ long, $0.2 \mathrm{~mm}$ in diameter) were fastened with a cyanoacrylic glue onto the three caudalmost whiskers of row $\mathrm{C}$

Table 1. Whisker configurations of the 25 mice used in the present study

\begin{tabular}{lllllll} 
& $\begin{array}{l}123 \\
\text { xxx }\end{array}$ & $\begin{array}{l}123 \\
\text { xxo }\end{array}$ & $\begin{array}{l}123 \\
\text { oxx }\end{array}$ & $\begin{array}{l}123 \\
\text { xox }\end{array}$ & $\begin{array}{l}123 \\
\text { oox }\end{array}$ & $\begin{array}{l}123 \\
\text { oxo }\end{array}$ \\
\hline $\mathrm{Ctr}$ & 4 & - & 1 & 2 & - & - \\
$1 \mathrm{~d}$ & 4 & 1 & - & - & - & - \\
$2 \mathrm{~d}$ & 4 & - & - & 2 & 1 & 1 \\
$4 \mathrm{~d}$ & - & 1 & 2 & - & 1 & 1
\end{tabular}

Whisker configurations of the left whiskerpad during active stimulation period are indicated by the groups of numbers listed at the first lines of the Table: "123" indicates the three caudalmost arcs; a cross below one of the numbers indicates that the whiskers of that arc were present, and a circle, that they were ausent (see Fig. 1 for numbering of arcs). For controls ( $\mathrm{Ctr}$ ) and for the three groups of passively stimulated animals (stimulated for 1,2 , or $4 \mathrm{~d}$ ), the numbers indicate the number of mice per whisker configuration. Animals listed in the first column were taken for the quantitative analysis. of the left whiskerpad (Fig. 2). An hour after recovery from anesthesia, the mice were placed in the Lausanne whisker stimulator-essentially an electromagnetic coil in which is a cylindrical cage with a diameter of $12.6 \mathrm{~cm}$-in which they moved freely. The stimulation consisted of magnetic field bursts that were delivered at $9 \mathrm{~Hz}$ (intensity of the field was $\sim 7 \times 10^{3} \mathrm{~A} / \mathrm{m}$, rms); the burst duration was $40 \mathrm{msec}$, during which the coil was energized with $\mathrm{AC}(50 \mathrm{~Hz})$ from the mains, and the interval between bursts was $70 \mathrm{msec}$ (Melzer et al., 1985a). The periods of passive stimulation lasted $1 \mathrm{~d}(n=5), 2 \mathrm{~d}(n=8)$, or $4 \mathrm{~d}(n=5)$ (see Table 1). The animals were checked for the presence of the metal pieces about every $6 \mathrm{hr}$. When whiskers that had lost their metal pieces were still present, the metal pieces were glued on again.

At the end of the passive stimulation period, the animals were kept immobilized without anesthesia for about $4 \mathrm{~min}$, during which the remaining metal pieces were gently removed with acetone. The mice displayed normal whisking activity. All the whiskers of the left whiskerpad were clipped except those belonging to the arcs of the whiskers that had been stimulated (Fig. 2). The whiskers of the contralateral side remained untouched.

The mice of the control group $(n=7)$ were nol exposed to passive stimulation. Whiskers of the left muzzle were clipped in order to obtain whisker configurations equivalent to those that were used in the experimental group (Table 1). Also in this group of mice, the clipping was done while the animal was kept immobilized without anesthesia.

All manipulations with whiskers and metal pieces were carried out with the help of a dissecting microscope.

Immediately upon termination of the first phase of the experiment, which for the control group consisted only of clipping of the whiskers, all animals of both groups were submitted to the second phase: the active stimulation after deoxyglucose injection.

Active stimulation and deoxyglucose method. Animals were injected intraperitoneally with $2-\left[1-{ }^{14} \mathrm{C}\right]$ deoxy-D-glucose $(16.5 \mu \mathrm{Ci} / 100 \mathrm{gm}$ body weight) in Ringer's solution and were introduced in a large cage containing a pile of wooden sticks (Fig. 2). Mice explored these objects, passing through holes while making active use of their vibrissae, for a period of $45 \mathrm{~min}$. They were continuously observed during this period, and in case an animal stopped being active, it was slightly pushed to continue its explorations. At the end of this period, they were deeply anesthetized with Nembutal $(60 \mathrm{mg} / \mathrm{kg}$, i.p.) and were perfused through the ascending aorta for a period of $10 \mathrm{~min}$ with freshly prepared fixative consisting of $3.3 \%$ formalin in $0.1 \mathrm{~m}$ phosphate buffer at $\mathrm{pH} 7.35$. The brain was removed and the forebrain was separated from the brainstem at the level of the superior colliculus. The forebrain was bisected midsagittally, and each hemisphere was fit to a small plastic wedge allowing tangential cutting of the barrel field. Tissue plus wedge were immersed and frozen in 2 -methylbutane at about $-70^{\circ} \mathrm{C}$. They were mounted onto 

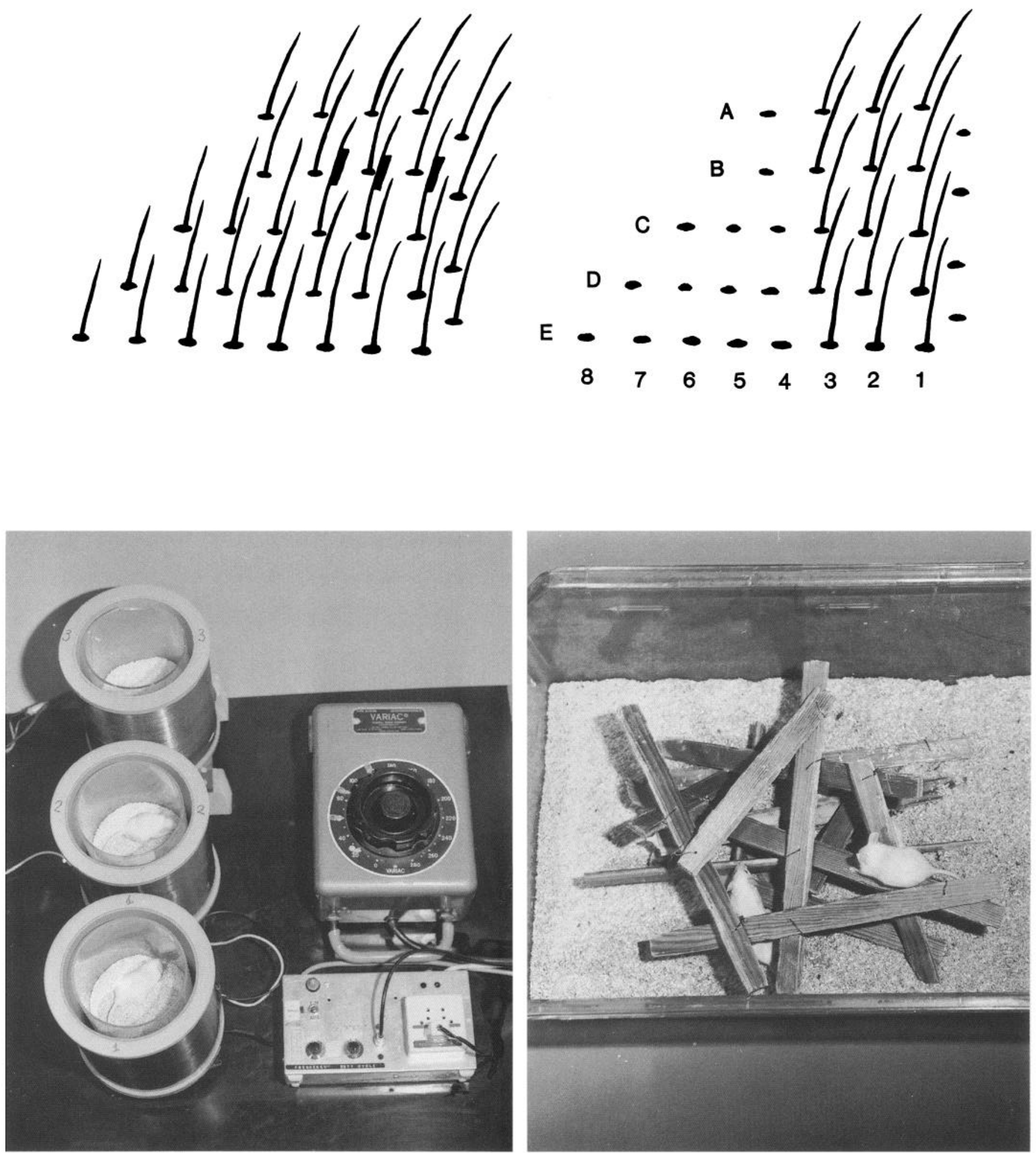

Figure 2. Illustrations of the animals' whisker configurations and the environments to which they are exposed during the two phases of the present experiments. Left panels, During the passive stimulation period (1,2, or 4 d), all whiskers are present (top); metal pieces were glued to the three caudal whiskers of row C (i.e., whiskers C1-3; see Fig. 1) at the left side, and then the animal was placed in one of the Lausanne whisker stimulators (bottom). Right panels, The active stimulation period just after the metal pieces had been removed from the three passively stimulated whiskers. The arc or arcs of whiskers that remained unclipped were dependent on which of the passively stimulated whiskers was still present at the moment the metal pieces were removed; the illustration at the top shows the pattern for the "ideal" case in which the animal kept all three passively stimulated whiskers; all other whiskers were clipped just prior to DG injection. During the active stimulation period, lasting 45 min, the mice explored the "stimulus-rich" cage (bottom). 


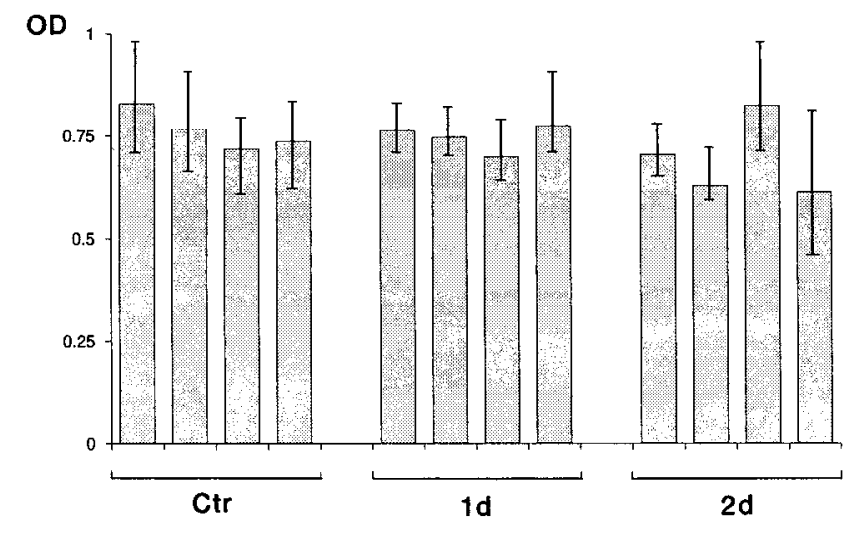

Figure 3. Graphic display of the mean OD values determined in the nonstimulated part of the barrel field (i.e., barrels C4,5, D4,5) in the animals used for the quantitative analysis (see Materials and Methods). Vertical lines indicate the range of the absolute values. Values are grouped according to experimental class: $C t r$, controls; $1 d$, animals that were passively stimulated for $1 \mathrm{~d} ; 2 d$, animals that were passively stimulated for $2 \mathrm{~d}$.

a cryostat object holder with cooled embedding matrix (M-1, Lipshaw). The brainstems were cut coronally; alternating sections were processed for cytochrome oxidase histochemistry (Wong-Riley, 1979).

The sections were cut at $20 \mu \mathrm{m}$, mounted on chilled gelatin-coated glass slides, and dried on a $60^{\circ} \mathrm{C}$ hot plate. They were then exposed to single-coated blue-base roentgen film (Cronex MRF 31, DuPont) at $4^{\circ} \mathrm{C}$ for $14 \mathrm{~d}$ according to the vacuum-contact method (Kloss et al., 1979). The films were developed at room temperature (Melzer et al., 1985a).

Thereafter, the sections were Nissl stained, dehydrated, and coverslipped. The outlines of the sections and the barrels were drawn using a microscope fitted with a camera lucida.

Qualitative analysis involved evaluation of stimulus-evoked and stimulus-independent deoxyglucose uptake patterns in both the control and the experimental groups (respectively, $n=7$ and $n=18$; see Table 1) in the barrel cortex and in the sensory trigeminal brainstem complex.

Quantification by densitometry involved the barrels of interest in the set of animals that had three arcs of whiskers present during the active stimulation period, that is, four controls, four mice passively stimulated for $1 \mathrm{~d}$, and four mice so stimulated for $2 \mathrm{~d}$ (Table 1; unfortunately, none of the mice stimulated for $4 \mathrm{~d}$ had kept all three stimulated whiskers). The superposition of the drawing containing the outlines of the barrels, and the digitized image of the corresponding autoradiogram allowed us to measure the mean transmitted light in a part of the autoradiogram corresponding to one barrel or sets of barrels. The following areas in layer IV were delineated: barrels whose whiskers were present during the active stimulation period, that is barrels A1-3, B1-3, C1-3, D1-3 and E1-3; barrels C4,5, and D4,5, which were used as reference; and a neighboring area on the film, not exposed to a section. Ideally all these barrels are present in a single section; however, in practice this was not always the case. Therefore, measurements were taken throughout a series of sections and parts of the available areas of interest were delineated in these individual sections.

These values of transmittance of light were transformed into optical density (OD) by taking the logarithm of the value outside the section minus the logarithm of the value of the measured barrel(s). The OD values proved to be normally distributed allowing statistical analysis based on parametric tests. Per animal, the mean OD was determined for the reference barrels (i.e., barrels C4,5 and D4,5). Figure 3 shows these values per animal grouped according to experimental class. There are no statistically significant differences between the mean $O D$ values of these classes. Per animal, we used the mean OD value of the reference barrels as the denominator in the ratio in which the ODs of the rows of stimulated barrels were the numerators (barrels A1-3, B1-3, C1-3, $\mathrm{D} 1-3$, and $\mathrm{E} 1-3$ ). We use this ratio in order to correct for the small differences in overall levels of DG uptake between animals. These ratios also followed a normal distribution.

From the ratios, the mean OD ratio for each row of stimulated barrels was computed per animal. These mean OD ratios of the control animals and those of the animals of the two experimental groups were used for statistical comparison. The statistical method used was a one-way anal- ysis of variance comprising the data of the three groups of animals, followed by Tukey's multiple comparison procedure with $5 \%$ overall type I error probability. For more detailed information, we performed separate $t$ tests on the values of the groups that had been shown to be significantly different in the multiple comparison procedure. Correlation coefficients between the mean OD ratios of row $C$ and those of the other rows were determined using the data of all quantitatively analyzed animals; these coefficients were tested for significance.

Further, a similar analysis was based on mean OD ratios of animals in which the mcasurcments of cach stimulatcd barrel werc kept scparate. These mean OD ratios were tested for significance using Tukey's multiple comparison procedure with $5 \%$ overall type I error probability.

Optical density was determíned using a TV camera-based image analysis system (ASBA Wild \& Leitz). The statistical analysis was performed using SAS ${ }^{\circledR}$ software (SAS Institute Inc., Cary, NC) running on a miniVax.

\section{Results}

The animals used in this study are listed in Table 1. They are grouped according to the number of days that the whiskers had been passively stimulated. Unfortunately, several mice lost one or more of their metal pieces, most often together with the whisker to which they were attached. When this happened, it was commonly during the first few hours of passive stimulation. As a consequence, we obtained a heterogeneous set of animals at the end of the period of passive stimulation. Notwithstanding this variability, the effect of passive whisker stimulation as observed in the autoradiograms of the barrel cortex from the experimental mice is qualitatively similar. Moreover, the effect did not seem to depend on the number of days the whiskers were passively stimulated. First, we present our observations in the cortex of the control mice and compare these with those in the animals that had been passively stimulated; second, we present the results of the quantitative analysis; and third, we present the observations in the trigeminal sensory complex in the brainstem.

\section{Barrel cortex: qualitative description}

Control animals. Superposition of the drawings of the barrel field on the corresponding autoradiograms reveals that stimulusdependent DG uplake in layer IV was confined, in the langential sense, to the barrels that correspond to the whiskers present during the period of active stimulation (Figs. 4, 5). The zone of stimulus-dependent DG uptake stretched in a continuous manner over the stimulated barrels. Although the overall DG uptake varied slightly between animals, in all mice the intensity of DG uptake diminished gradually from the medial barrels (those of rows $\mathrm{D}$ and $\mathrm{E}$ ) toward the more lateral barrels (those of row $\mathrm{A}$ ). In the cases of stimulation of three arcs of whiskers, the highest level of DG uptake was centered over barrels of the second (middle) arc (Fig. 5).

Stimulus-dependent DG uptake was maximal in layer IV, but was present throughout the entire radial extent of the barrel column (Fig. 6). The stimulus-dependent DG uptake was markedly higher in the supragranular layers than in the infragranular layers (where it was highest in deep layer V). The gradient of DG uplake within the arcs of stimulated barrels, as described above for layer IV, was also present in the other cortical layers. In line with this, the representations of whiskers of rows $A$ and $B$ were sometimes difficult to observe in the infragranular layers. Interestingly, at the border between layers IV and V, the pattern of DG uptake became discontinuous and revealed individual rows of whisker representations.

Passively stimulated animals. The stimulus-dependent DG uptake in layer IV of the barrel cortex was restricted, in a tan- 

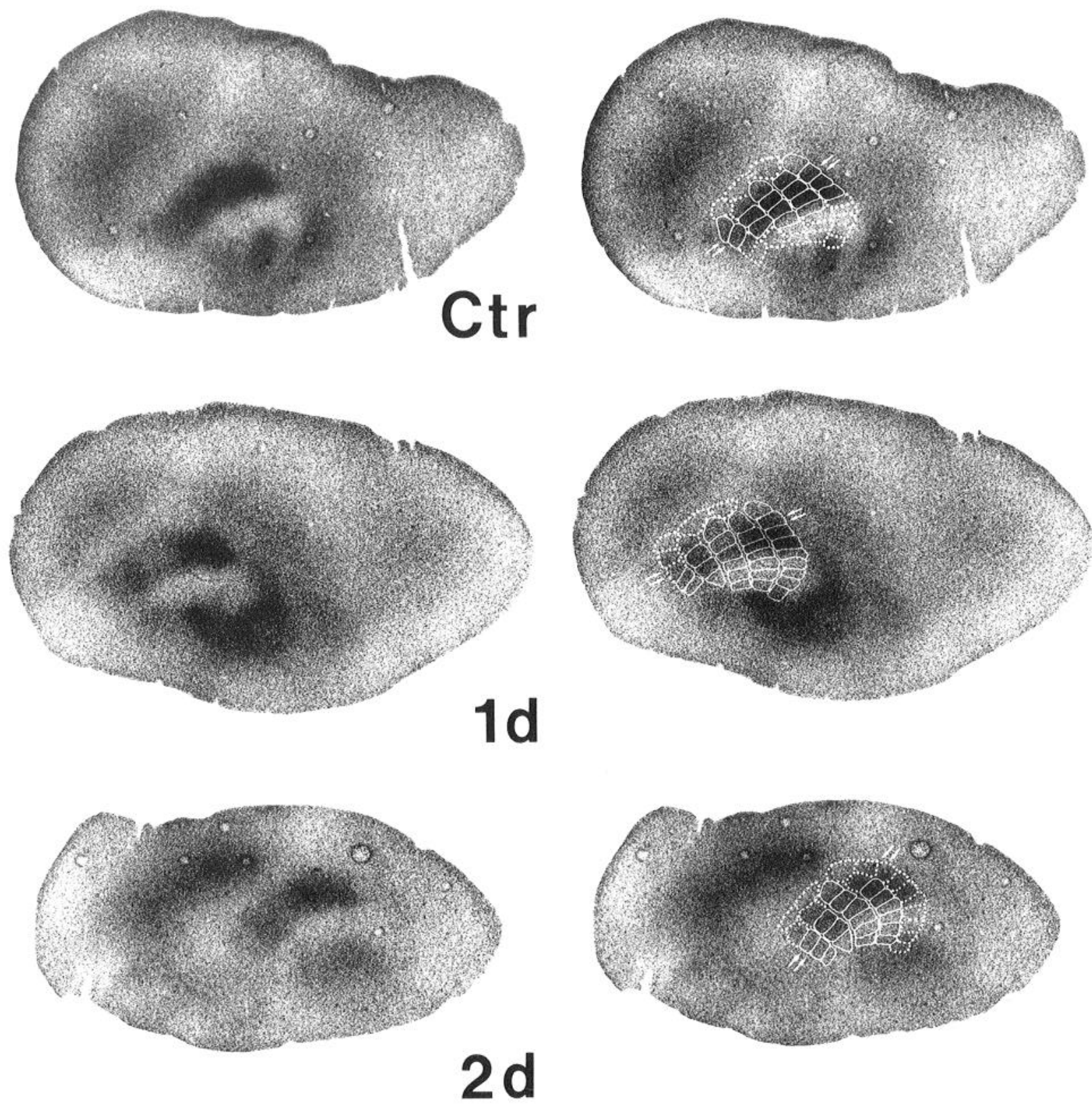

$2 \mathrm{~d}$
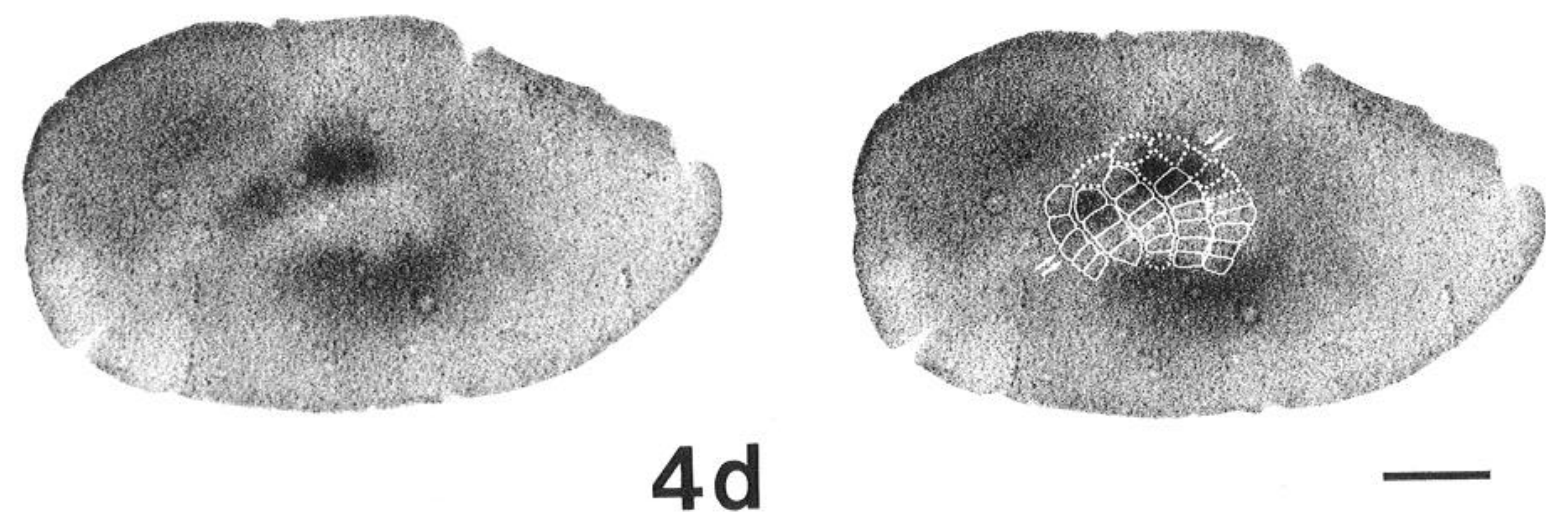

row were taken from a section of a control animal (Ctr) of which the three caudal arcs of whiskers were present during autoradiograms of the first those of the second row, from a mouse whose whiskers $\mathrm{C} 1-3$ had been passively stimulated for $1 \mathrm{~d}$ prior to the DG experiment; those of the third row, from a mouse whose whiskers $\mathrm{C} 1-3$ had been passively stimulated for $2 \mathrm{~d}$; those of the fourth row, from a mouse whose whiskers $\mathrm{C} 1$ and $\mathrm{C} 2$ had been passively stimulated for $4 \mathrm{~d}$. The right-hand column shows the same autoradiograms superimposed with the reconstruction of the barrel field: barrels whose contours were drawn with a solid white line are those observed in the corresponding Nissl-stained section; outlines of barrels observed in neighboring sections are drawn with a broken line. The two pairs of white arrows indicate the area in the autoradiogram that was scanned during densitometry, yielding the profiles displayed in Figure 7. Scale bar, $1 \mathrm{~mm}$. 

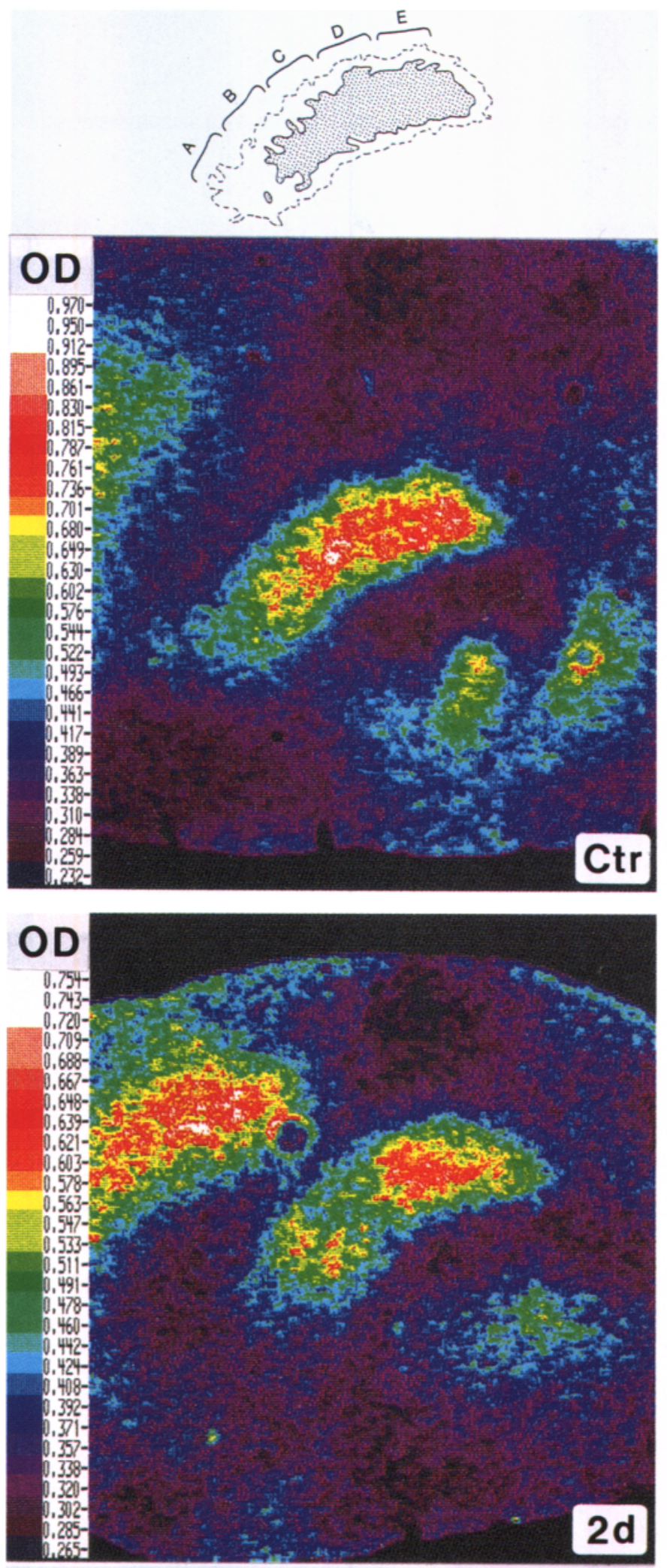

$$
\text { (2) }
$$
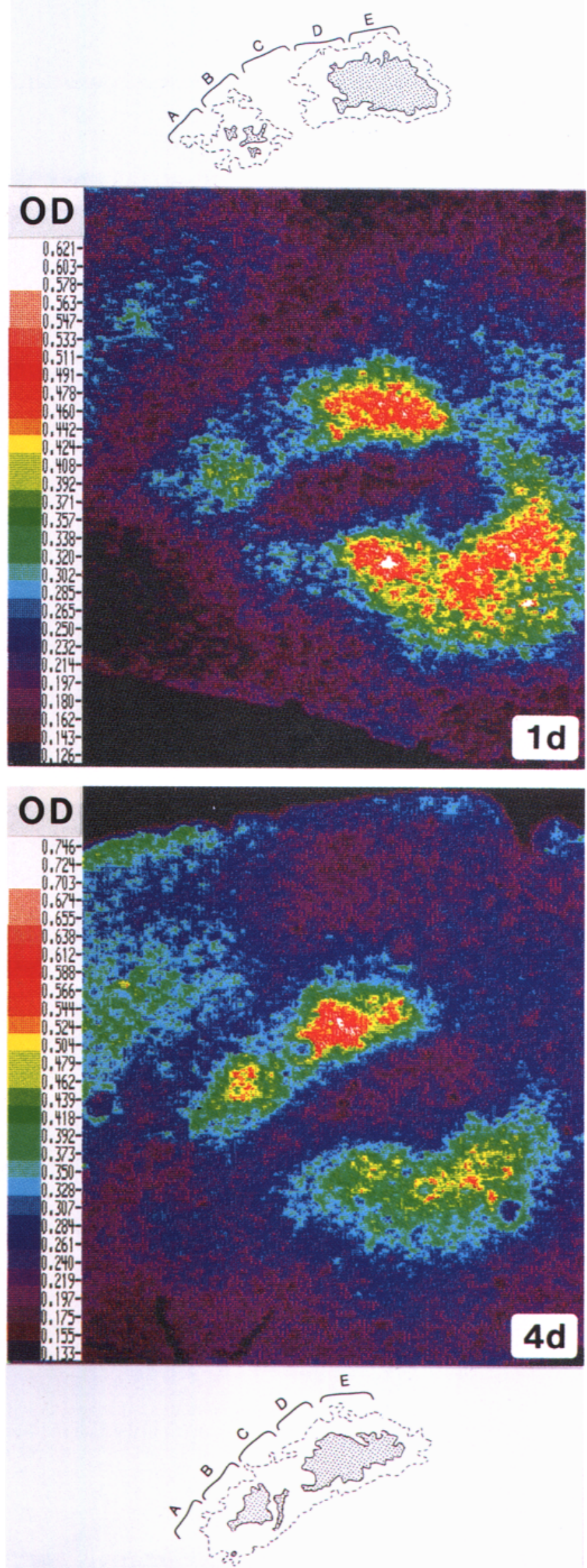
gential sense, to the barrels whose whiskers were present during the period of active stimulation. The DG uptake in the barrels of row $C$ of which the whiskers had been passively stimulated was very low, especially if compared with the DG uptake in the stimulated barrels of row D in the same autoradiogram (Fig. 4). This relative decrease of DG uptake in the barrels of row $C$ was similar in all experimental animals. The DG uptake in the passively stimulated barrels can reach a level that is lower than that in the barrels of row B. This was observed in about $50 \%$ of the experimental animals; in the other cases the level of DG uptake in the barrels of row $C$ was still a bit higher than that of the barrels of row $\mathrm{B}$. With respect to this phenomenon, there is no correlation with the period of stimulation.

The decrease in DG uptake in the passively stimulated barrels can be followed in tangential sections through supra- and infragranular layers (Fig. 6). However, in the infragranular layers of some animals it could not be recognized as a dip in the center of the band of stimulus-evoked DG uptake due to a very weak level of stimulus-evoked DG uptake over the representations of rows $\mathrm{A}$ and $\mathrm{B}$.

\section{Barrel cortex: quantitative analysis}

Figure 7 gives four profiles of the transmittance of light measured across each of the marked areas of the autoradiograms of Figure 4. In these profiles a low transmittance is expressed as a high value, which corresponds to a high level of DG uptake. In the autoradiogram of the control animal, the peak value was situated over barrels of row D, from which there is a gradual decrease in DG uptake over the more lateral barrels (rows $\mathrm{C}$, $B$, and A) and the more medial barrels of row $E$. The profile of the autoradiogram of the animal passively stimulated for $1 \mathrm{~d}$ showed a steep drop at the transition between rows D and C. This drop is present but less pronounced in the profile taken from the autoradiogram of the animal passively stimulated for $2 \mathrm{~d}$. The profile of the animal passively stimulated for $4 \mathrm{~d}$ has a bimodal aspect with the tops centered above barrels of rows $\mathrm{B}$ and $\mathrm{D} / \mathrm{E}$; the dip coincides with the passively stimulated barrel of row $\mathrm{C}$.

For the statistical comparison, we selected those animals of which whiskers C1-3 had been stimulated continuously throughout the passive stimulation period (see Materials and Methods). Figure 8 gives, per group of animals, the mean OD ratio for each row. The values in the control group show the gradient in OD along the stimulated arc of barrels: row $\mathrm{A}$ has the lowest DG uptake, while row D expresses the highest level of DG uptake (Fig. 8, top). This distribution is clearly modified in the two groups of experimental animals. For both groups, the multiple comparison procedure showed a significant decrease of the OD ratios of row $C$ as compared to these ratios in the control mice. In the animals passively stimulated for $24 \mathrm{hr}$, there is a decrease in DG uptake in row D that is significantly different from row D ratios of the control group; in the animals that were passively stimulated for $2 \mathrm{~d}$, the OD ratios of row $\mathrm{D}$
Table 2. Results of tests for correlation between mean $\mathrm{OD}$ ratios of barrels of row $C$ and those of the other rows

\begin{tabular}{lll} 
& \multicolumn{2}{l}{ Correlation } \\
\cline { 2 - 3 } Rows & $r$ & $p$ \\
\hline A-C & 0.09 & 0.774 \\
B-C & 0.44 & 0.149 \\
D-C & 0.75 & 0.005 \\
E-C & 0.59 & 0.045
\end{tabular}

Data include the values of all mice that were quantitatively analyzed, including control mice (see Materials and Methods). The second column lists the correlation coefficient $(r)$ obtained in each of the tests; the third column lists the level of significance.

are not significantly different from controls. However, the distribution of the ratios of row D in the three groups of animals parallels the distribution of these values of row $C$ (Fig. 8, bottom). The other ratios of the experimental animals were shown not to be significantly different from comparable ratios of the control mice, nor do they differ between the two experimental groups.

Tests for linear correlation were performed on the mean OD ratios for the values of row $\mathrm{C}$ barrels from individual control and experimental animals with the values of the other barrel rows. Table 2 lists the results of these tests and shows that the values of rows C and D are most significantly correlated (Fig. 9).

The final part of our quantitative analysis (Fig. 10) consists of the comparison of OD ratios of individual barrels in thosc rows that had shown significant differences when our comparison took into account global row values (see above). The aim was to identify the barrels that were most affected by the passive stimulation. The values were obtained from the same group of animals used for the other quantitative analyses. Comparing the values in control mice, the results show that the highest DG uptake was localized in the barrels of the second arc, that is, barrels C2 and D2. In the two groups of experimental mice, the decrease in DG uptake was present in all three barrels of row C. This drop is more marked in the animals passively stimulated for $1 \mathrm{~d}$ than in those stimulated for $2 \mathrm{~d}$. Statistical comparison demonstrated that the values of $\mathrm{C} 1$ and $\mathrm{C} 2$ differed significantly from controls in both experimental groups of animals.

The $\mathrm{OD}$ ratios of the barrels of row $\mathrm{D}$ followed the changes induced in the barrels of row $\mathrm{C}$. It is only the drop in the ratio for barrel D2 in the animals stimulated for $1 \mathrm{~d}$ that resulted in a value significantly different from those in controls.

\section{Brainstem}

Of the four subnuclei of the trigeminal nerve, only subnuclei interpolaris and caudalis show a delineated area of stimulusevoked DG uptake; the small size of the subnucleus principalis as seen in a coronal plane is probably the reason why, in the mouse, the zone of stimulus-evoked DG uptake is less clearly

\section{$\leftarrow$}

Figure 5. Pseudocolor display of the four autoradiograms shown in Figure 4. Ctr, control animal; $1 d$, animal passively stimulated for $1 \mathrm{~d}$, $2 d$, animal passively stimulated for $2 \mathrm{~d} ; 4 d$, animal passively stimulated for $4 \mathrm{~d}$. Color distribution was chosen such that the lowest $O D$ value over the section was rendered purple; the highest $\mathrm{OD}$ value, white (see color bars). The drawings above (top row) and below (bottom row) the color images are based on the outlines (outer contour) of the light blue pixels in the part of the color image reflecting stimulus-dependent DG uptake in the barrels corresponding to the posterior whiskers of rows A-E. The inner contours are drawn around the yellow pixels in the above-mentioned zones. For further details, compare with the drawings of the barrel field of these same hemispheres as displayed in the right column of Figurc 4 and thosc in Figure 7. 
Figure 6. Four sets of autoradiograms from serial tangentially cut sections through the right hemispheres of four mice. Autoradiograms are displayed as negatives; the illustrations were obtained by inserting the autoradiograms into a photographic enlarger. Material was taken from the same four animals from which autoradiograms are displayed in Figures 4 and 5; Ctr, series from control animal; $1 d$ and $2 d$, series from mice of which whiskers $\mathrm{Cl}-3$ were passively stimulated for 1 or $2 \mathrm{~d}$, respectively; $4 d$, series from mouse of which whiskers $\mathrm{C} 1$ and $\mathrm{C} 2$ were passively stimulated for $4 \mathrm{~d}$. For each series, the zone of stimulus-evoked DG uptake that corresponds to the arcs of whiskers present during the active stimulation period is situated between the two arrows placed in the same autoradiograms as those displayed as positives in Figure 4. From here the zone of stimulus-evoked DG uptake can be followed into more superficial and deeper cortical layers; vertical white lines mark the site between two adjacent sections where the center of this zone (i.e., the part representing follicles of row $\mathrm{C}$ ) crossed a boundary between two layers that are indicated left and right of the bar. Layer boundaries were determined in the corresponding Nissl-stained sections. The autoradiograms indicated with an open triangle are displayed (at a higher magnification) at the bottom of the corresponding set. $W M$, white matter. Scale bar: $4 \mathrm{~mm}$ for the autoradiograms displayed at low magnification, $1.8 \mathrm{~mm}$ for the autoradiograms displayed at high magnification.

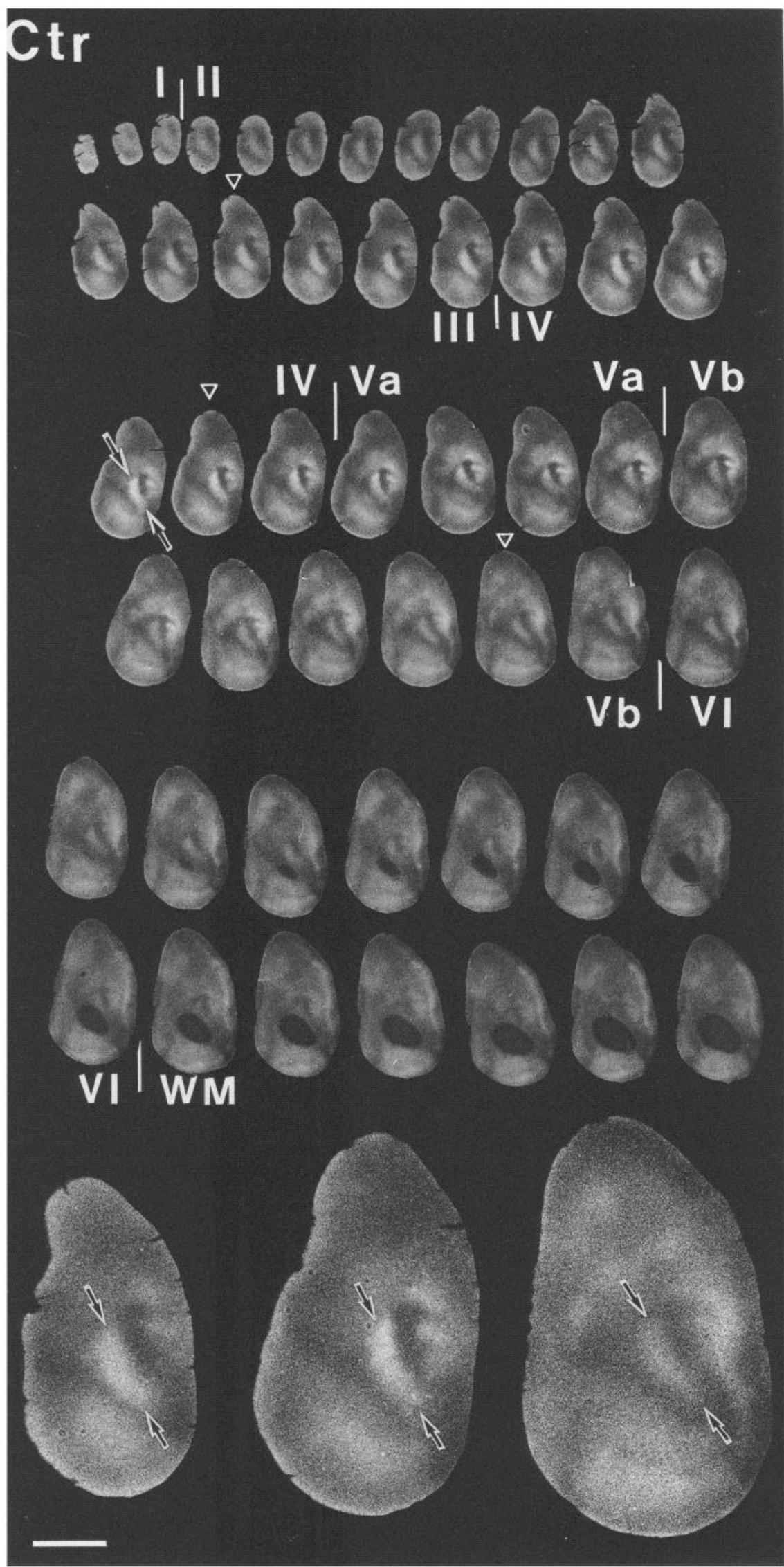




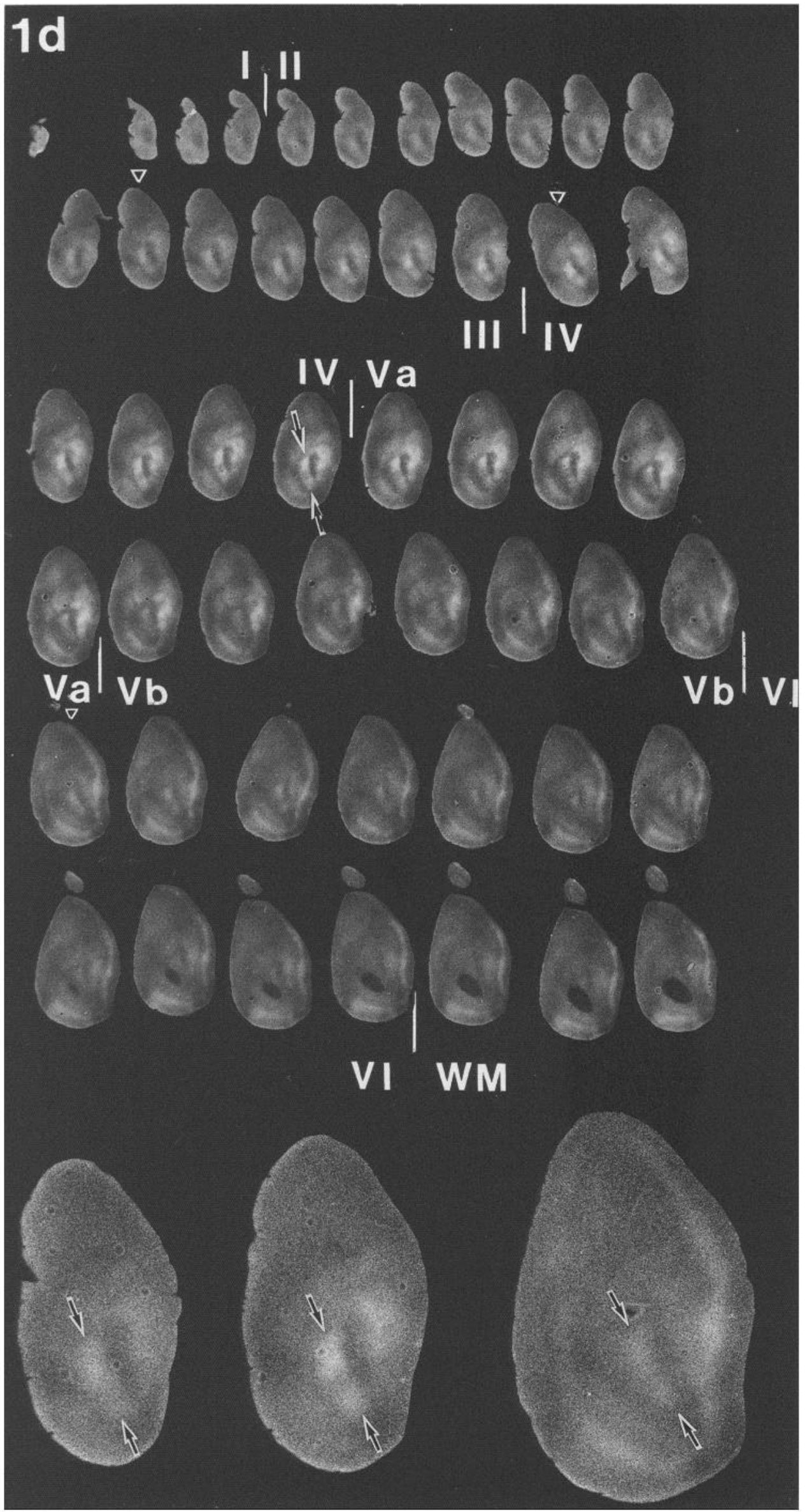




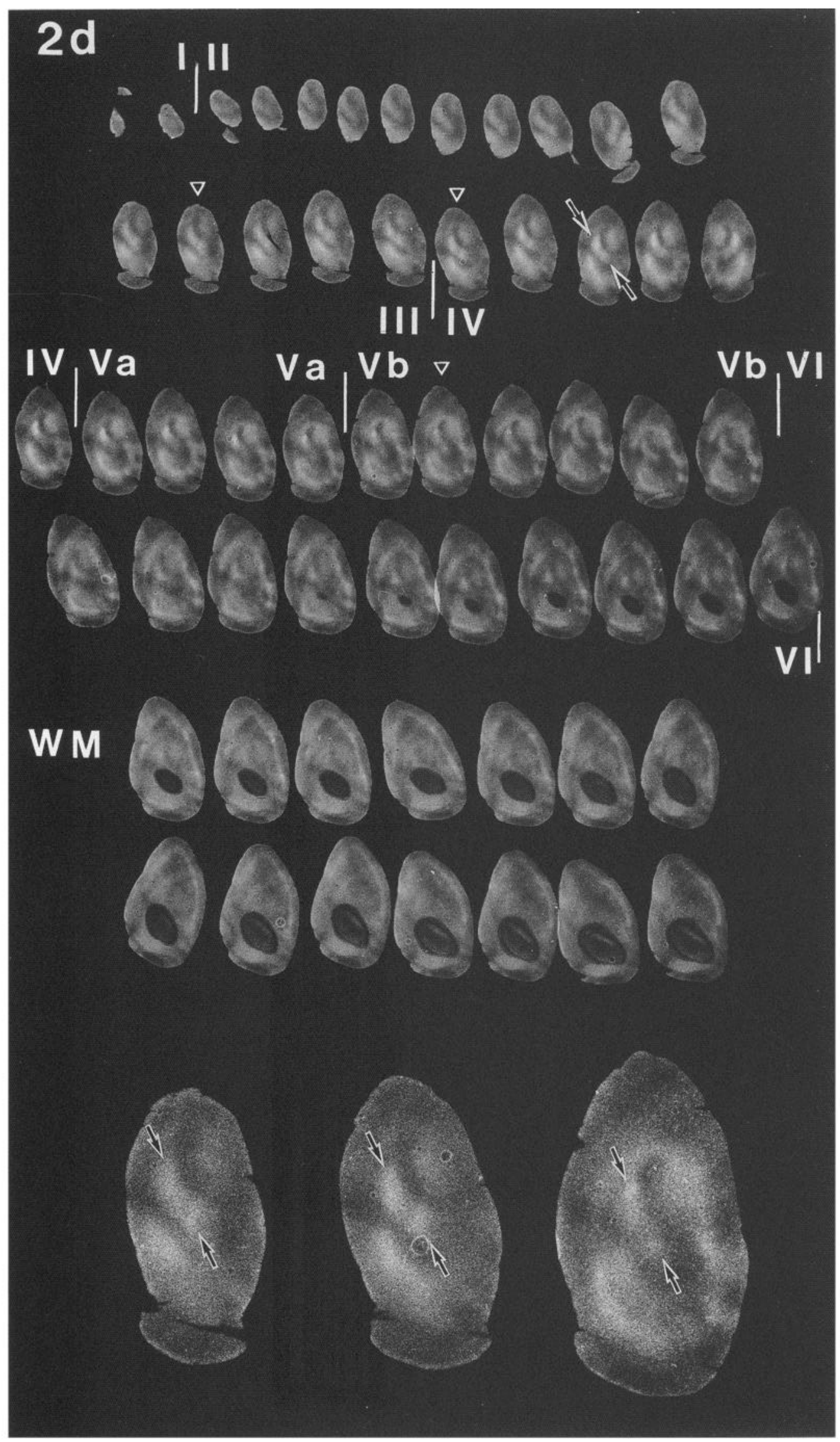




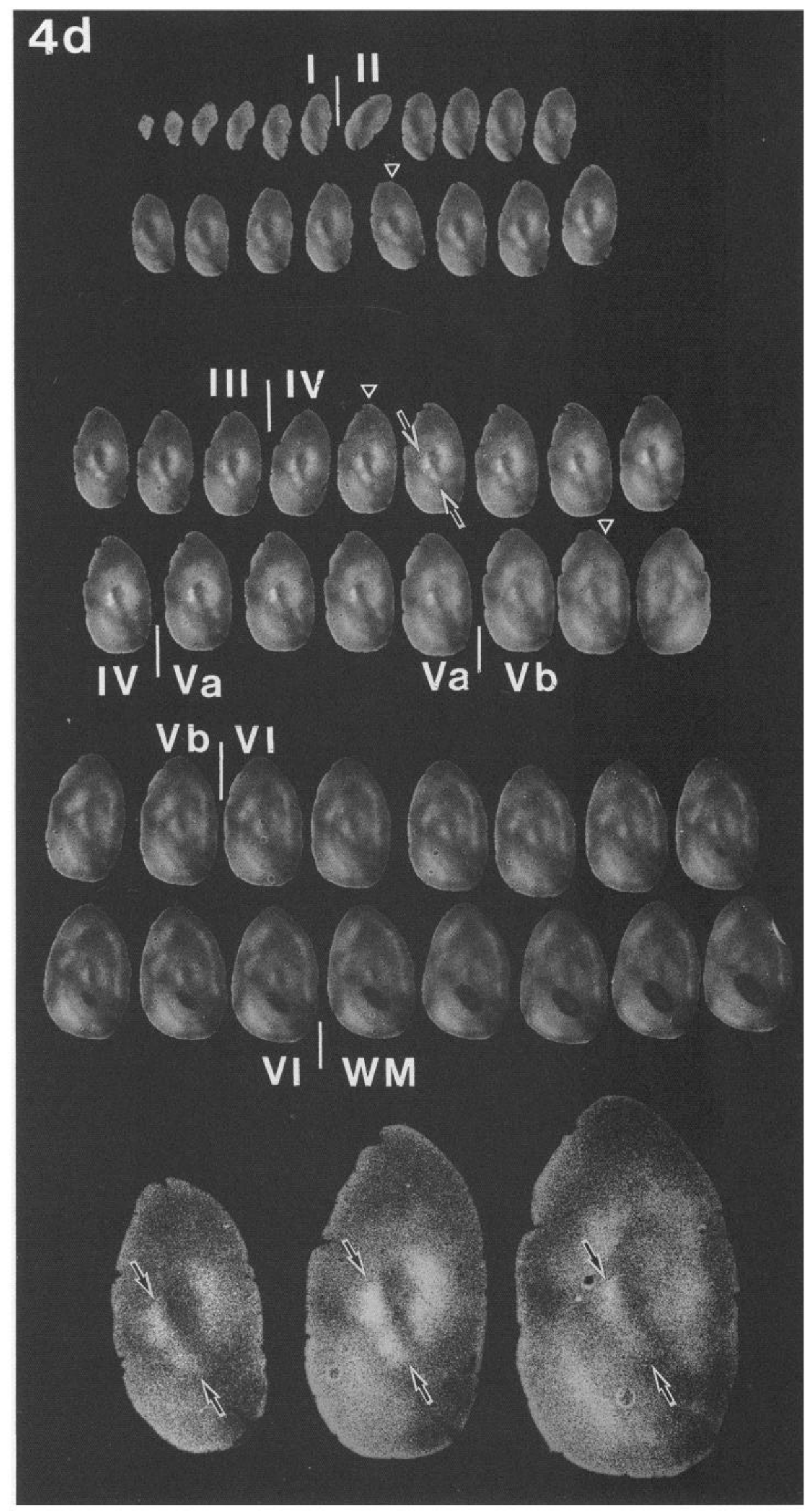



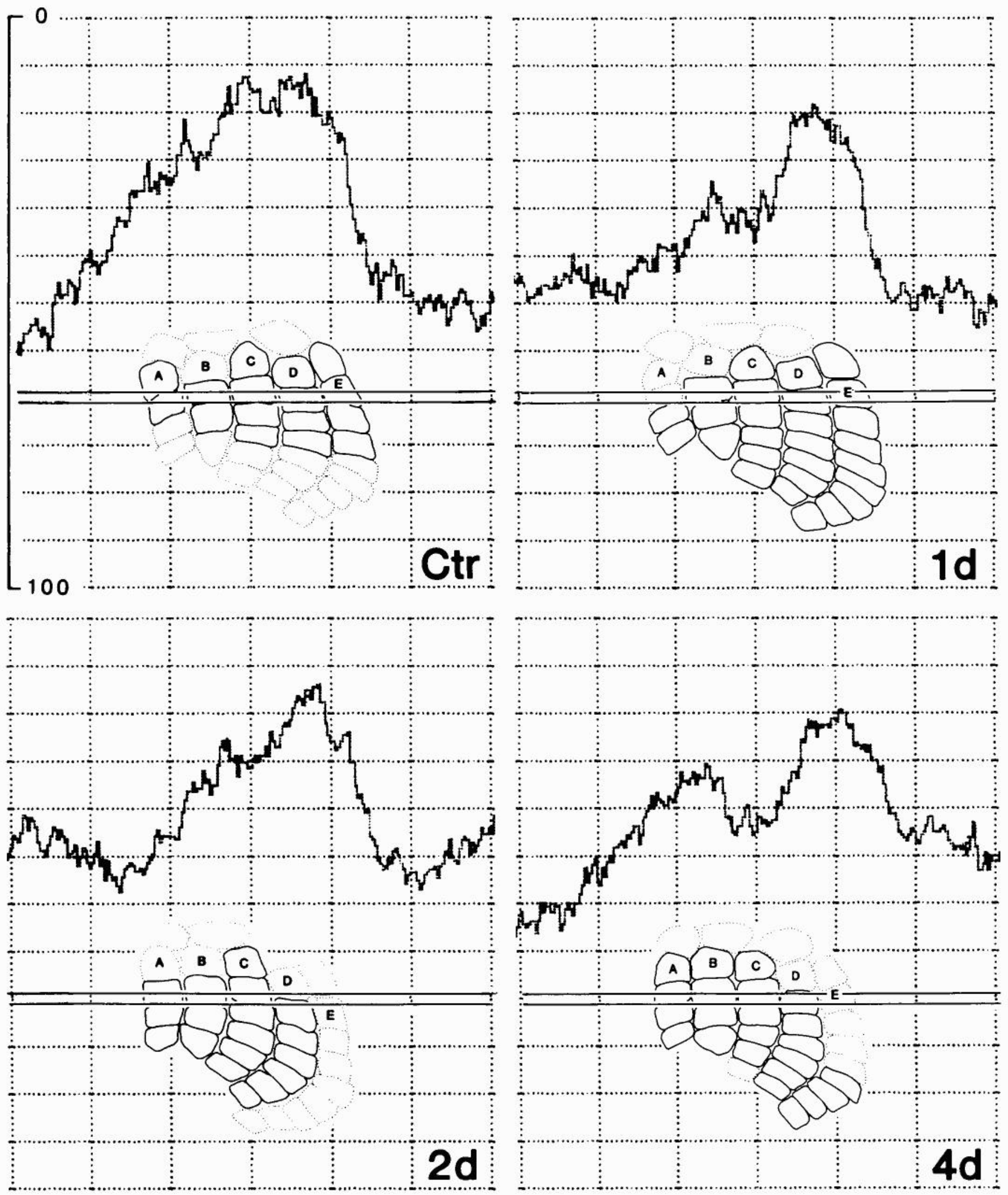

Figure 7. Four graphs of mean transmittance of light measured in one-pixel-wide strips positioned perpendicular to the parallel lines crossing the barrel fields drawn below each graph. The ordinate shows percentage of transmitted light; for each panel, $80 \%$ transmittance refers to light passing through a part of the film not exposed to a section; $10 \%$, to light passing through the densest area in the autoradiogram. The measurements were taken from the autoradiograms displayed in Figure 4 (Ctr, control animal; $1 d$, mouse stimulated for $1 \mathrm{~d}, 2 d$, mouse stimulated for $2 \mathrm{~d} ; 4 d$, mouse stimulated for $4 \mathrm{~d}$ ). In the reconstruction of the barrel field below the graphs, barrels that were visible in the corresponding Nissl-stained section are drawn with a solid line; those present in the adjacent sections, with broken lines. We aimed to sample from the same area of the barrel field in all four cases. 

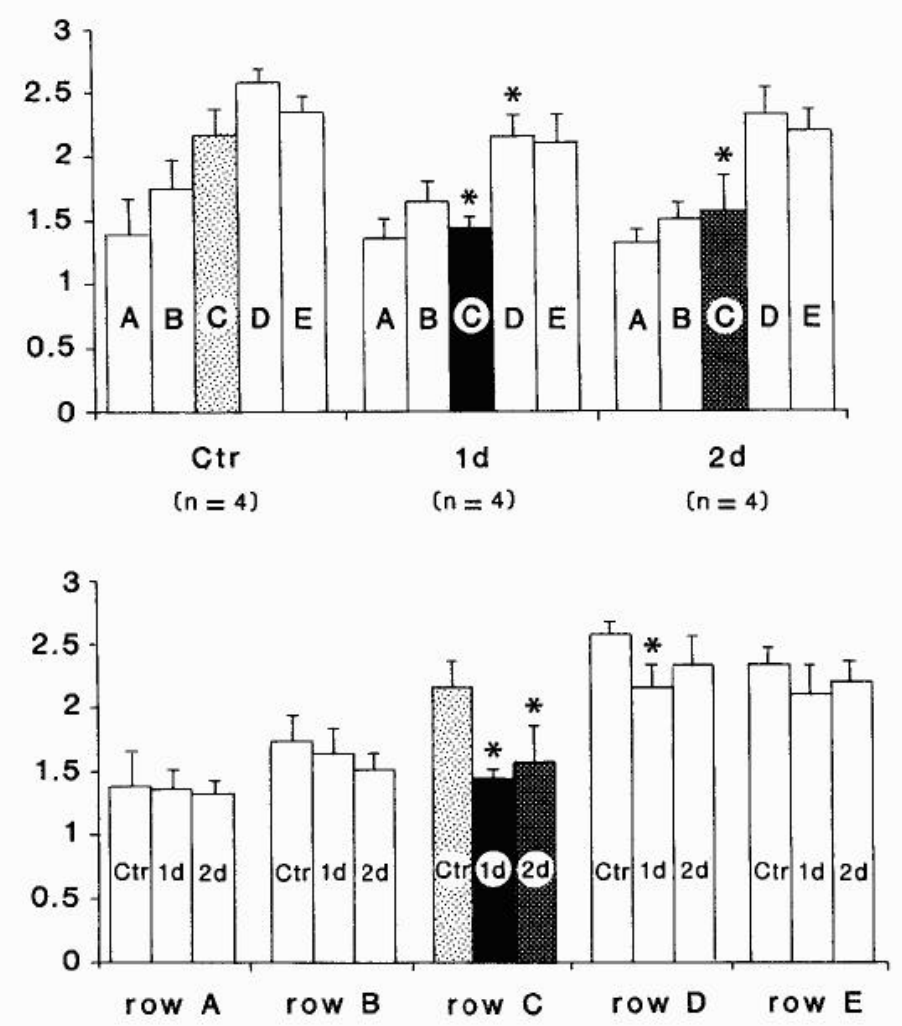

Figure 8. Two graphic displays of the results of the quantitative analysis. In both graphs, columns denote the mean values calculated, for each animal, from the mean OD ratio as determined by the measurements taken from zones of the autoradiograms corresponding to barrels A1-3, B1-3, C1-3, D1-3, and E1-3 and from the nonstimulated part of the barrel field, that is, barrels $\mathrm{C} 4,5$ and D4,5. Vertical lines indicate SDs. In the upper graph, columns are grouped per experimental class: $C t r$, controls; $1 d, 1 \mathrm{~d}$ of passive stimulation; $2 d, 2 \mathrm{~d}$ of passive stimulation; $n$ indicates the number of animals analyzed per group. In the lower graph, the same results are displayed for each experimental class per row. Asterisks indicate the values in the experimental animals that are significantly lower than the values obtained for the same rows in the control animals: for row $C, I d, p=0.0008$; for row $D, I d, p=0.006$; for row $C, 2 d, p=0.016$ (as determined by $t$ test).

delimited here. Stimulus-evoked DG uptake in subnucleus oralis is hardly discernable. For a detailed description of stimulusevoked DG uptake in the trigeminal brainstem nuclei of the mouse see S. B. Rao et al., unpublished observations.

In subnuclei interpolaris and caudalis, stimulus-evoked DG uptake was present throughout most of their rostrocaudal extent. This zone shifted in position within subnucleus caudalis from a medial position at its rostral pole to a more lateral position more caudally. In subnucleus interpolaris, the zone of stimulusdependent DG uptake was situated at its lateral border, forming a curved strip covering the representation of the caudal whiskers as seen in adjacent cytochrome oxidase sections.

In subnuclei interpolaris and caudalis of the control animals, stimulus-evoked DG uptake formed a continuous strip that expressed a gradient in uptake, with the higher values dorsally and lower values more ventrally. This reflects a higher uptake in the representation of whiskers of rows $C$ and $D$ and a lower uptake in the representations of whiskers of rows A, B, and E (Fig. 11). This gradient was present in all the sections that showed a stimulus-evoked uptake. This pattern of DG uptake is in agreement with the gradient in DG uptake observed in the barrel cortex (see above).

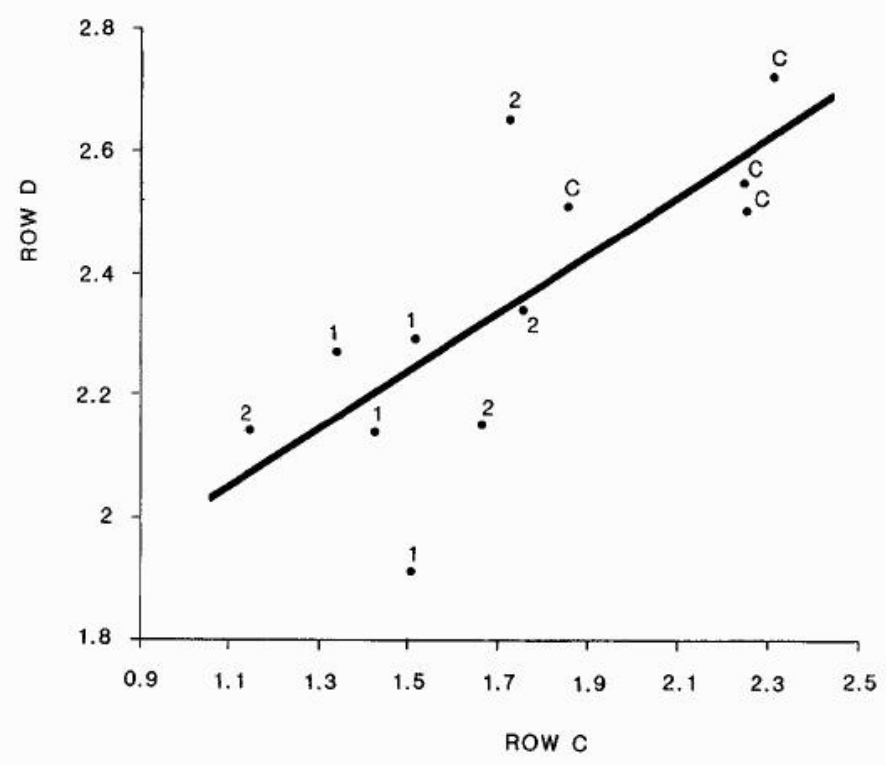

Figure 9. Scatter graph showing the correlation in levels of DG uptake between rows $C$ and $D$ as determined from the relative $O D$ values measured in the autoradiograms over barrels $\mathrm{Cl}-3$ and over barrels D1-3 (see Results). Data include the measurements of the control animals $(C)$ and the experimental animals stimulated for $1 \mathrm{~d}(l)$ or $2 \mathrm{~d}$ (2).

In the experimental animals, we distinguished two patterns of stimulus-evoked DG uptake. One is similar to the strip described for the control animals, with its continuous gradient of DG uptake. In the other pattern, DG uptake is also confined to a strip but shows a decrease in DG uptake at its center flanked by higher uptake dorsally as well as ventrally. This dip in DG uptake corresponds to the representation of the row $C$ whiskers. Both types of patterns were observed in the three groups of experimental animals and could therefore not be correlated with the length of the period of passive stimulation or with the number of arcs present during active stimulation. The sex of the animal played no role, either. Combining these results with those from the cortex, it is interesting to note that both types of patterns of DG uptake in the brainstem are invariably accompanied by a dip in DG uptake in the cortical representation of the passively stimulated whiskers of row $\mathrm{C}$.

\section{Discussion}

In this study, we have used the autoradiographic DG method to demonstrate modifications in metabolic activity in the whisker-to-barrel pathway in the adult behaving mouse. Our interest was in alterations of that activity caused by prolonged passive whisker stimulation.

We opted for a paradigm in which the mouse actively explored a stimulus-rich environment during the DG phase of the experiment. The animals were continuously observed in order to check whether they indeed remained active for the $45 \mathrm{~min}$. The pattern of stimulus-dependent DG uptake in the brainstem and barrel cortex of control mice was, in qualitative terms, invariable, although the overall levels of DG uptake differed slightly between mice. OD values of stimulated parts of the barrel cortex were made relative to OD values of nonstimulated barrels. In this way we obtained a set of data that showed little variation between animals of the same group. This is interesting, since one might have expected that the "amount" of sensory stimu- 


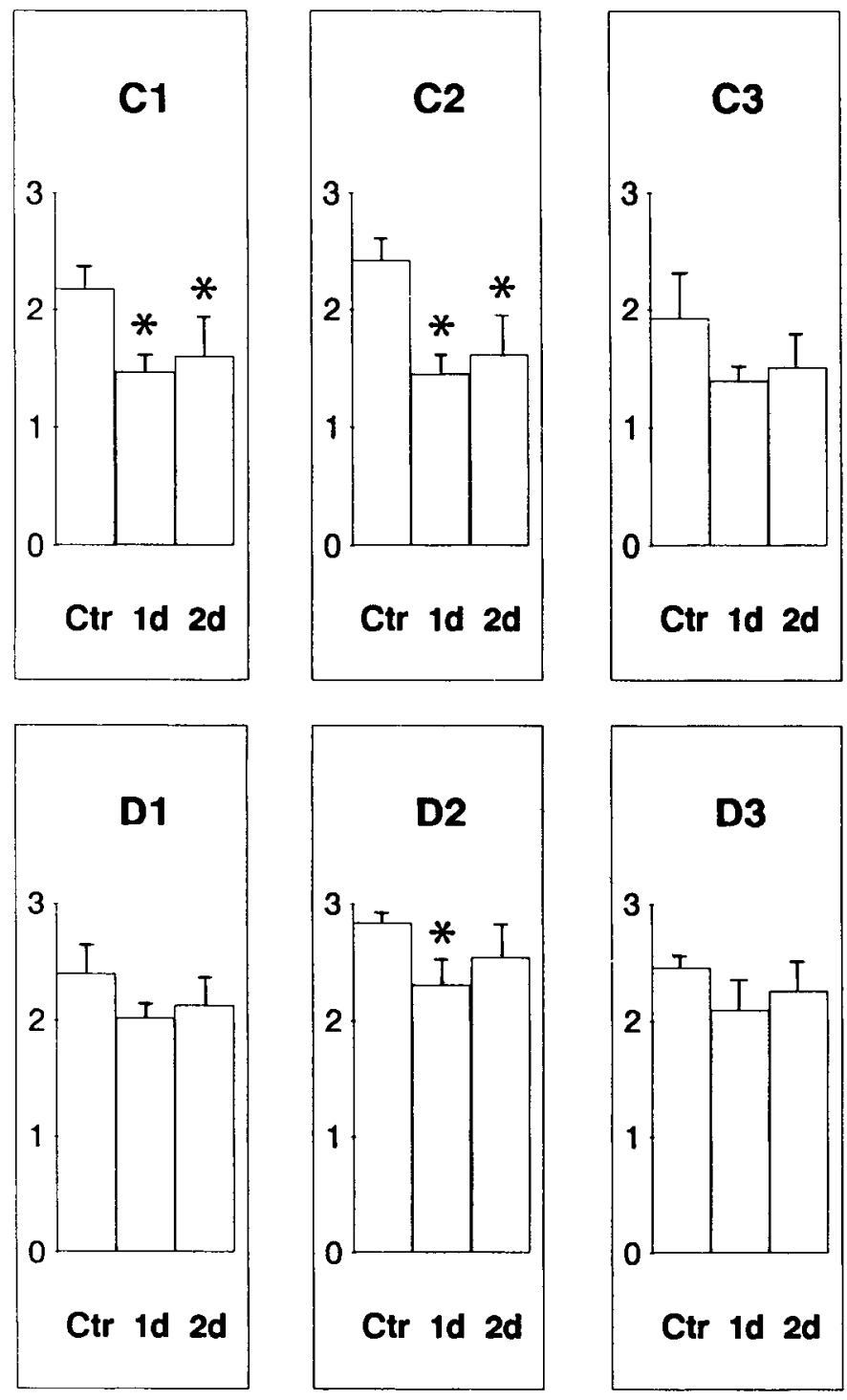

Figure 10. Graphic display of the mean values calculated from the mean OD ratio as determined per animal from the measurements taken from zones of the autoradiograms corresponding to barrels $\mathrm{Cl}-3$ and D1-3 and from the nonstimulated part of the barrel field, that is, barrels $\mathrm{C} 4,5$ and D4,5. Vertical lines indicate the SD of the mean. Ctr, means calculated from data of control animals; $I d$, those from animals passively stimulated for $1 \mathrm{~d} ; 2 d$, those from animals passively stimulated for $2 \mathrm{~d}$. Asterisks indicate the values in the experimental animals that are significantly $(p<0.04)$ lower than the values obtained in the control animals.

lation would differ between freely moving animals and, accordingly, would have resulted in variability among, for example, the control mice This consistency holds for the comparison of the data obtained from different rows, and those from different arcs.

After the autoradiographic DG method had been established (Sokoloff et al., 1977), several studies demonstrated that DG uptake in the CNS reflects the level of neuronal activity (Schwartz et al., 1979; Kadekaro et al., 1985; Webster et al., 1985). Webster et al. (1985) exposed the auditory pathway of the cat to a highintensity pure tone superimposed on a low-intensity white noise. Thus, they were able to show that a band of high DG uptake in the inferior colliculus coincided with the neurophysiological localization of the isofrequency contour corresponding to the pure tone in question. Moreover, this band of high DG uptake was flanked by a zone in which the level of DG uptake was lower than in the other parts of the inferior colliculus. It was argued that the zone of low DG uptake represented the "inhibitory side band" (Webster et al., 1985). The study was a good example of the usefulness of the DG technique in the functional analysis of sensory pathways: besides mapping sites of neuronal activity, it enables one to estimate relative levels of neuronal activity.

In an earlier study on the whisker-to-barrel pathway, we used the same passive stimulus that we applied in the present analysis, but for only $45 \mathrm{~min}$. Animals were restrained and, at the beginning of the stimulation period, injected with $D G$. This procedure yielded in an increased DG uptake in a column of cortex, comprising in layer IV the barrel corresponding to the stimulated whisker (Melzer et al., 1985a). In another study, the intensity of DG uptake in layer IV was shown to be directly proportional to the intensity of stimulation (Melzer et al., 1985b). We concluded that DG uptake in the barrel cortex reflects the level of peripheral sensory activity.

Based on these considerations of what DG levels may reflect in terms of neuronal activity, we proposed that the present observation of a decrease of DG uptake in the barrel corresponding to the chronically "prestimulated" follicle reflects a decrease in neuronal activity within this barrel. Which factor(s) could determine this relative decrease? One possibility is a lowering in peripheral sensory activity in the chronically stimulated whisker follicle (e.g., due to "motor or sensory receptor fatigue").

Several observations make the above interpretation unlikely. At the moment of metal unglueing, we noticed no difference in whisking activity between stimulated versus nonstimulated whiskers in the same animal. A second argument against a mere peripheral origin of our observation stems from our earlier plasticity studies using the GAD antibody. We found that whisker follicle removal in the adult mouse results in a decrease in GAD immunoreactivity in the barrel cortex (Welker et al., 1989a), whereas chronic whisker stimulation results in a GAD increase (Welker et al., 1989b). After arrest of peripheral stimulation, GAD levels returned to normal within a period of $4 \mathrm{~d}$. Based on these results, we concluded (Welker et al., 1990a) that GAD immunoreactivity in the barrel field is an indicator of peripheral sensory activity: it is low when there is no activity (follicle removal) and high when there is an excess of activity (chronic stimulation). The temporary nature of the latter effect indicates that the peripheral drive should be present continuously, if the GAD activity is to be maintained at an increased level. This conclusion is in agreement with the observation of Hendry and Jones (1988) in the primary visual cortex, where eyelid closure leads to a drop in GABA immunoreactivity in the ocular dominance columns corresponding to the closed eye, whereas subsequent eyelid opening restores GABA levels to normal (Hendry and Jones, 1988).

In the light of the above, we propose that the decrease in DG uptake in the barrels corresponding to the passively stimulated whiskers is due not to a peripheral mechanism, but to a mechanism of plasticity whose substrate is to be found within the CNS. Plasticity in the somatosensory system of adult mammals has been shown to occur at cortical and subcortical levels (for a review, see Kaas, 1991). In the whisker-to-barrel pathway of the adult rat, sensory deprivation leads to decreased GAD immunoreactivity not only in the barrel cortex but also in the ventrobasal nucleus of the thalamus (Land and Akhtar, 1987; Akhtar and Land, 1991). In the same pathway, however, mod- 

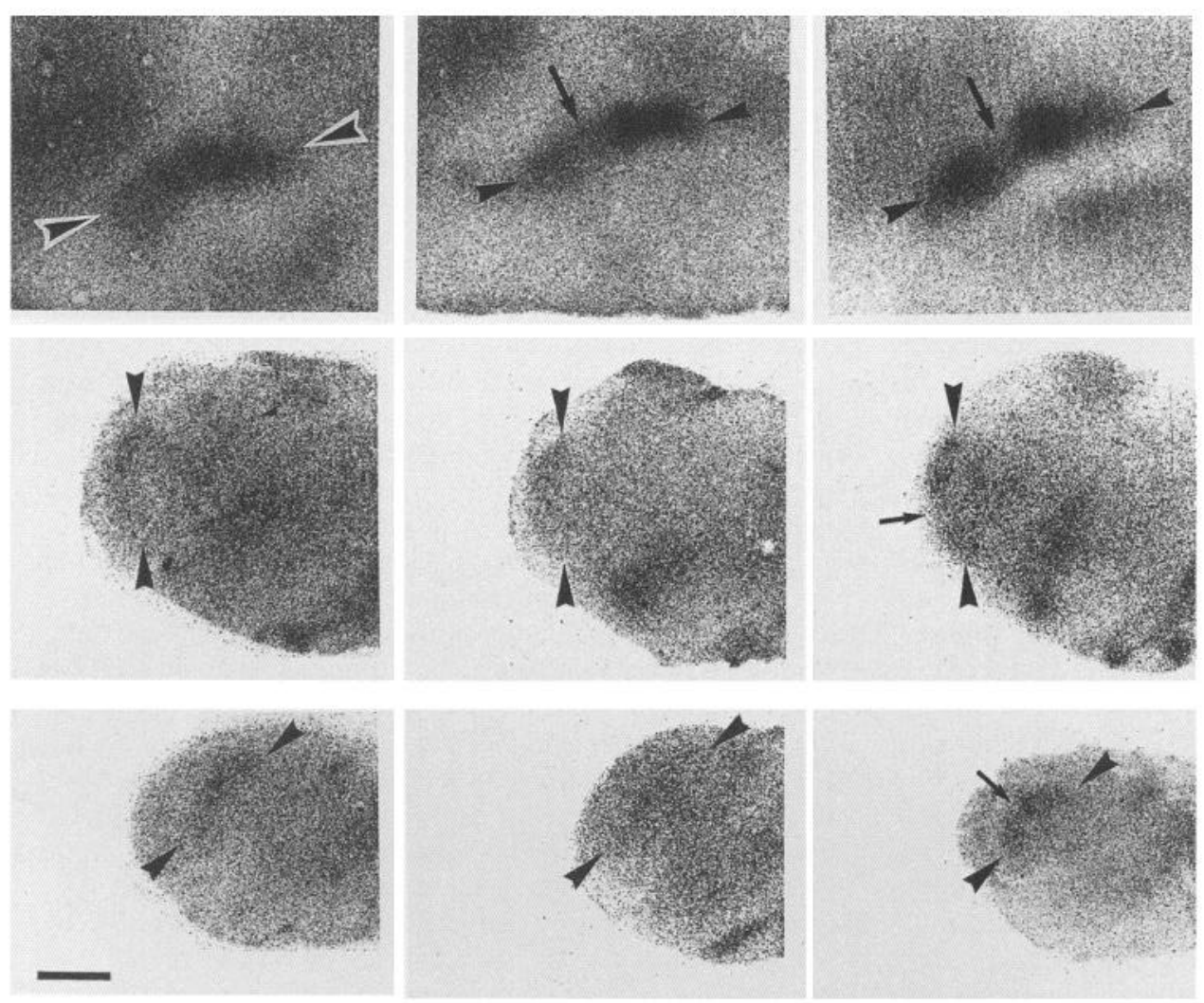

$$
\text { Ctr : } 123
$$

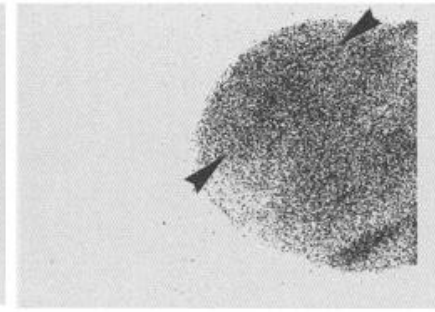

$4 d:-23$
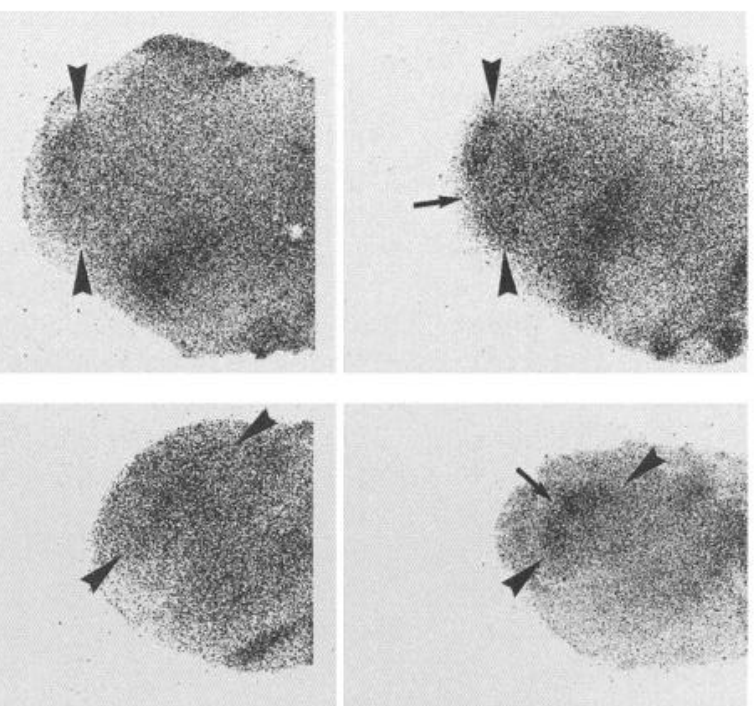

1d : 12-
Ctr : $\mathrm{n}=7$

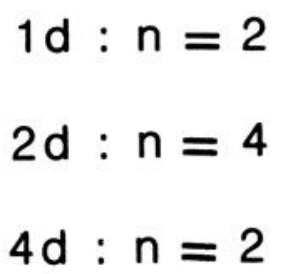

$1 d: n=3$

$2 d: n=3$
Figure 11. Three sets of autoradiograms from sections through three stations of the whisker-to-barrel pathway, serving to illustrate two types of pattern of DG uptake within the lower stations of the pathway. Top row, sections cut tangentially through layer IV of the barrel cortex; middle row, coronal sections through subnucleus interpolaris of the trigeminal nerve; bottom row, coronal sections through subnucleus caudalis of the trigeminal nerve. The autoradiograms in the left column were taken from a control animal; in the center col$u m n$, from a mouse that was stimulated for $4 \mathrm{~d}$; in the right column, from an animal that was stimulated for $1 \mathrm{~d}$. The arcs of whiskers present at the moment of active stimulation are indicated just below each column. The zones of stimulus-dependent DG uptake are between two arrowheads in the center column, the subnuclei interpolaris and caudalis show a gradient of stimulus-evoked DG uptake that is comparable to that seen in controls (left column), whereas in cortex there is a clear "dip" at the level of row C (arrow). In other animals, such as the one illustrated in the right col$u m n$, such a dip was present in the brainstem nuclei as well (arrows). Scale bar, $500 \mu \mathrm{m}$ (pertains to all panels). The data below the autoradiograms list the total number of animals in which we observed the illustrated DG patterns per group $(C t r$, control animals; $1 d$, mice passively stimulated for $1 \mathrm{~d} ; 2 d$, mice passively stimulated for $2 \mathrm{~d} ; 4 d$, mice passively stimulated for $4 \mathrm{~d}$ ). The total number of experimental animals here is 17 (not 18), as the brainstem of one did not lend itself to analysis. ifications in DG uptake due to increased sensory stimulation have been reported to occur only at the cortical level (Hand and Hand, 1983). In the present study, we describe modifications in the barrel cortex and subnuclei caudalis and interpolaris in the sensory trigeminal brainstem complex. We have no similar data on two other stations of the pathway, that is, the subnucleus principalis and the ventrobasal nucleus of the thalamus. These two latter stations are of importance in the feedforward projections to the cortex (Rhoades et al., 1987). Therefore, our study is not conclusive with respect to whether the decrease in DG uptake in the stimulated barrels in SI is due to a cortical mechanism or is the consequence of subcortical modifications.

The cortical effect was observed in all our experimental animals and did not seem to be different between animals stimulated for 1,2 , or $4 \mathrm{~d}$. The decrease in DG uptake was not restricted to layer IV, but was observed throughout the entire barrel column. Thus, the effect is expressed not only in the layer containing the main neuronal recipients of the specific thalamic projections (White, 1979; Frost and Caviness, 1980), but also in the layers containing the somata of the cortical projection neurons (Wise and Jones, 1976, 1977). From this, one may expect to find functional modifications in areas of the brain that receive projections from the barrel cortex (Welker et al., 1988; see also below).

Interestingly, while prolonged whisker stimulation increased GAD immunoreactivity in layer IV as well as in supragranular layers, we did not observe such changes in the infragranular layers. In the present study, the decrease in DG uptake was throughout all cortical layers. The decreased DG uptake in the infragranular layers could be explained by a decrease in its excitatory input from supra- and/or granular layers. This could be due to an increased inhibition of the spiny stellate cells of layer IV that have been shown to send their axons toward infragranular layers (Lorente de Nó, 1922; Woolsey et al., 1975).

In about half of the experimental animals, the cortical effect was accompanied by a decrease in DG uptake at the level of the representation of the passively stimulated follicles of row $\mathrm{C}$ in the subnuclei caudalis and interpolaris of the sensory trigeminal complex, whereas in the other half these parts of the brainstem did not show a change with respect to control animals. 
The cortex, however, showed a modification of DG uptake in barrels of row $\mathrm{C}$ in all experimental mice. The constancy in the cortical effect of passive stimulation on the one hand, and the variability in the effect in the trigeminal subnuclei in the brainstem on the other hand, points to a curious independence of the cortical effect on the situation in these two lower relays. It may well be that the brainstem effect is due to the cortical input to thcse nuclci. That this projection could have such a circumscribed effect within a subnucleus is in agreement with our observation of a one-to-one relationship between a cortical barrel column and the brainstem representation of its whisker follicle (Welker et al., 1988). Obviously, this does not explain why in the other half of the experimental mice, the two sensory trigeminal brainstem nuclei did not show any effect of chronic stimulation.

The popularity of the whisker-to-barrel pathway as an experimental model in systems neuroscience is greatly due to the visibility of the central representations of the individual whisker follicles. From the beginning, the morphological neatness of the one whisker/one barrel relationship demonstrated in DG studies was striking (Hand, 1981; Melzer et al., 1985a; Chmielowska et al., 1986). However, functionally the pathway is not simply a collection of isolated single-whisker/single-barrel pipelines, but has been shown to possess features that can be described as follicular cross-talk, by which we mean the integration of inputs arising from different follicles. This integration could occur at any level of the whisker-to-barrel pathway and beyond; however, this does not occur at its peripheral origin, since recording in the trigeminal nerve has shown that axons convey information arising from a single whisker follicle only (Simons, 1985). Since some of our present observations will be interpreted in terms of follicular cross-talk, we here review some of the relevant literature.

In the mouse, stimulation of three whiskers within the same row led to higher levels of stimulus-evoked DG uptake than did stimulation of a single whisker (Melzer et al., 1985a). Simons and Carvell (1989) have studied single- and multiunit responses in the rat barrel cortex in the context of a "conditioning-test paradigm." They displaced two adjacent whiskers one after another (first the "conditioning whisker" and, 10 misec later, the "test whisker") and compared the responses obtained after displacement of the test whisker alone with those evoked by displacing the test whisker after the displacement of the conditioning whisker. For some of the cortical units, the effect differed depending on which whisker was the conditioning whisker. Quantitative analysis showed that for the regular-spiking units in layer IV and lower layer III, conditioning with a more rostral whisker evokes less inhibition than conditioning with a caudal whisker. Similarly, conditioning with a more dorsal whisker evokes less inhibition than conditioning with a whisker from a more ventral row.

Bernardo et al. (1990) reported that the intrinsic connectivity of the barrel cortex of the mouse is characterized by an anisotropic pattern of inter-barrel column connectivity. Small injections of HRP centered at the border between layers III and IV revealed that barrel columns are preferentially connected with their neighbors of the same row. With respect to connections across rows, they showed that barrel columns project more strongly toward neighbors representing follicles in more ventral rows than toward neighbors representing follicles in more dorsal rows.

An analysis of response properties of single units in the barrel cortex of the mouse demonstrated anisotropy in the response characteristics of units in all cortical layers (Welker et al., 1990b). In a given barrel column, all neurons respond with the shortest latency upon deflection of the corresponding whisker. Stimulation of neighboring whiskers of the same row elicits responses that occur earlier than those evoked by stimulation of whiskers of the same arc. In general the number of spikes evoked by a peripheral stimulus is positively correlated with the latency at which the response occurs. Therefore the "in-row" whiskers elicit more responses than the "in-arc" whiskers.

The above anisotropies in connectivity and physiological properties of cortical neurons may well underlie the observation that, in the case of stimulation of three arcs of whiskers, the barrels of the arc in the middle have the highest level of DG uptake. Also, the gradient in levels of DG uptake as observed across the rows could be the consequence of anisotropy of connections between barrel columns as described by Bernardo et al. (1990). Such a gradient was also observed by McCasland and Woolsey (1988), who examined stimulus-dependent DG patterns in the barrel cortex of freely moving mice. In both studies, DG was found to be more accumulated in barrels corresponding to the more ventral rows of whisker follicles than in those of the more dorsal rows. An alternative explanation for this gradicnt could be that in the behaving mouse the more ventral whiskers encountered objects in the exploration of the pile of wooden sticks more often than the dorsal ones. The three-dimensional aspect of the environment in which the mice were placed in the present study makes this explanation less likely. However, a peripheral origin of the observed DG gradient cannot be excluded and may indeed correlate with the differences in innervation density between whisker follicles (Welker and Van der Loos, 1986).

The examples of follicular cross-talk are also important in the light of the results of our quantitative analysis that showed that besides the modification in DG uptake in the barrels of the passively stimulated follicles of row $C$, the level of metabolic activity in the barrel columns of row $\mathrm{D}$ was also significantly affected in the animals stimulated for $1 \mathrm{~d}$. The decrease in DG uptake in row $D$ was not significant in the animals stimulated for $2 \mathrm{~d}$. This difference in the effects in row D may well be due to the higher level of DG uptake in the barrels of row $C$ in mice stimulated for $2 \mathrm{~d}$ in comparison with that in the animals stimulated for $1 \mathrm{~d}$. In our material, including the data of all mice quantified, DG uptake in row D is significantly correlated with that in row $C$. We have previously shown that the effect of chronic passive stimulation upon GAD immunoreactivity is restricted to the barrel columns corresponding to the stimulated whiskers. We therefore propose that the effect in DG uptake in row $\mathrm{D}$ is a conscquence of the GAD modifications in the barrel columns of row $\mathrm{C}$. This $\mathrm{C}$-to-D relationship strikingly fits with the anisotropy in the projections between barrel columns of different rows referred to above.

Armstrong-James et al. (1991) argued that the surround receptive fields of cortical neurons are the consequence of intracortical signal transfer. These authors propose that the occurrence of stimulus-evoked activity, for example, of a unit in a row $\mathrm{D}$ barrel column caused by stimulation of a row $\mathrm{C}$ whisker, is due to information transfer from the row $\mathrm{C}$ barrel column toward the unit in row D. Our present observations fit that interpretation: the increased GAD immunoreactivity in the passively stimulated barrels of row $\mathrm{C}$ would not only lower neuronal activity within the other parts of the corresponding barrel col- 
umn, but would also deprive units in the barrel columns of row $D$ of much of their normally occurring row $C$ input. An alternative explanation for the effects observed in barrels of row $D$ is provided by the results of the conditioning-test paradigm of Simons and Carvell (1989; see above): the inhibition of units in barrels of row $\mathrm{D}$ by units in barrel columns of row $\mathrm{C}$ could have become enhanced through the increased GAD levels in the latter barrels. This increase in surround inhibition could explain the observed decrease in DG uptake in barrels of row D. A third possibility is that the effect in barrels of row D may be duc to follicular cross-talk at subcortical lcvels.

Whatever the substrate of follicular cross-talk may be, the effect of passive stimulation of the follicles of row $\mathrm{C}$ upon the barrels of row $\mathrm{D}$ may be a first demonstration of this aspect of the functional organization of the whisker-to-barrel pathway in the behaving mouse.

It is tempting to interpret the observed decrease in metabolic activity in the passively stimulated barrels as a sign of cortical habituation. Originally, habituation was defined as a decrease in response upon repeated peripheral sensory stimulation and has been considered to be a primitive form of learning (Thompson and Spencer, 1966). In our experiment, there is a difference between the stimulus with which we may have habituated the pathway and the stimulus that evoked the DG uptake. The former was an artificial passive stimulus (duration, $40 \mathrm{msec}$; frequency, $9 \mathrm{~Hz}$ ); the latter was an active stimulation elicited by the animal's whisking as it explored a novel environment. Because of this essential difference between the two types of stimulation, we prefer to use unspecific habituation as the term best suited to describe our interpretation.

Although we consider our stimulation as an exaggeration of what may happen in a natural setting, in which the animal whisks at a frequency not very different from the repetition rate of the stimulus applied, we do realize that a continuous stimulation for as many as 4 days is unnatural. We have described our prolonged stimulation as passive stimulation: the animal is exposed to it, whether it likes it or not, and it does not occur in the context of a behavioral task.

In this light it is interesting to mention the result of a chronic stimulation experiment in the monkey (Jenkins et al., 1990). These authors described a major expansion of the representation of stimulated fingers in SI only in the case in which the animal was trained to pay attention to the delivered stimulus; when it was not forced to do so, no significant expansion was observed. We therefore may expect different results when applying our form of passive stimulation in the context of a behavioral test situation in which the stimulation would make "sense" to the animal.

In summary, we hypothesize that prolonged, passive whisker stimulation activates a cortical mechanism that results in an unspecific sensory habituation for the whisker follicle so stimulated. This mechanism, for which we propose the dynamics of the GABAcrgic innervation of the barrel to be at least partially responsible, would function as a gate for peripheral sensory activity to enter cortical circuitry and thereby modulate its influence on further intracortical and subcortical processing.

\section{References}

Akhtar ND, Land PW (1991) Activity-dependent regulation of glutamic acid decarboxylase in the rat barrel cortex: effects of neonatal versus adult sensory deprivation. J Comp Neurol 307:200-213.

Armstrong-James M, Callahan CA, Friedman MA (1991) Thalamo- cortical processing of vibrissal information in the rat. I. Intracortical origins of surround but not centre-receptive fields of layer IV neurones in the rat S1 barrel field cortex. J Comp Neurol 303:193-210.

Bernardo KL, McCasland JS, Woolsey TA (1990) Local axonal trajectories in mouse barrel cortex. Exp Brain Res 82:247-253.

Calford MB, Tweedale R (1988) Immediate and chronic changes in responses of somatosensory cortex in adult flying-fox after digit amputation. Nature 332:446-448.

Chmielowska J, Kossut M, Chmielowska M (1986) Single vibrissal cortical column in the mouse labeled with 2-deoxyglucose. Exp Brain Res 63:607-619.

Dykes RW, Landry P, Metherate R, Hicks TP (1984) Functional role of GABA in cat primary somatosensory cortex: shaping receptive fields of cortical neurons. J Neurophysiol 52:1066-1093.

Frost DO, Caviness VS Jr (1980) Radial organization of thalamic projections to the neocortex in the mouse. J Comp Neurol 194:369393.

Hand CL, Hand PJ (1983) Chronic vibrissa activation produces decreased glucose utilization in SI cortex but not in subcortical levels of rat vibrissa-cortical barrel system. Soc Neurosci Abstr 9:379.

Hand PJ (1981) The deoxyglucose method. In: Neuroanatomical tracttracing methods (Heimer L, Robards MJ, eds), pp 511-538. New York: Plenum.

Hendry SHC, Jones EG (1986) Reduction in number of immunostained GABAergic neurones in deprived-eye dominance columns of monkey area 17. Nature 320:750-753.

Hendry SHC, Jones EG (1988) Activity-dependent regulation of GABA expression in the visual cortex of adult monkeys. Neuron 1:701-712.

Jenkins WM, Merzenich MM, Ochs MT, Allard T, Guíc-Robles E (1990) Functional reorganization of primary somatosensory cortex in adult owl monkeys after behaviorally controlled tactile stimulation. J Neurophysiol 63:82-104.

Kaas JH (1991) Plasticity of sensory and motor maps in adult mammals. Annu Rev Neurosci 14:137-167.

Kadekaro M, Crane AM, Sokoloff L (1985) Differential effects of electrical stimulation of sciatic nerve on metabolic activity in spinal cord and dorsal root ganglion in the rat. Proc Natl Acad Sci USA 82:60106013.

Kloss G, Kellner H-M, Kötter C (1979) Vakuum-Kontakt-Methode bei der Makroautoradiographie. Z Naturforsch [C]28:468.

Land PW, Akhtar ND (1987) Chronic sensory deprivation affects cytochrome oxidase staining and glutamic acid decarboxylase immunoreactivity in adult rat ventrobasal thalamus. Brain Res 425: 178-181.

Lorente de Nó R (1922) La corteze cerebral del ratón. Trab Lab Invest Biol Univ Madrid 20:41-78.

McCasland JS, Woolsey TA (1988) High-resolution 2-deoxyglucose mapping of functional cortical columns in mouse barrel cortex. $\mathbf{J}$ Comp Neurol 278:555-569.

Melzer P, Van der Loos H, Dörfl J, Welker E, Robert P, Emery D, Berrini JC (1985a) A magnetic device to stimulate selected whiskers of freely moving or restrained small rodents: its application in a deoxyglucose study. Brain Res 348:229-240.

Melzer P, Welker E, Dörfl J, Van der Loos H (1985b) The dependence of stimulus-evoked responses in the barrelfield (BF) of the mouse on the intensity of vibrissa stimulation: a deoxyglucose (DG) study. Neurosci Lett [Suppl] 22:S424.

Merzenich MM, Kaas, JH, Wall J, Nelson RJ, Sur M, Felleman D (1983a) Topographic reorganization of somatosensory cortical areas $3 \mathrm{~b}$ and $1 \mathrm{in}$ adult monkeys following restricted deafferentation. Neuroscience 8:33-55.

Merzenich MM, Kaas JH, Wall JT, Sur M, Nelson RJ, Felleman DJ (1983b) Progression of change following median nerve section in the cortical representation of the hand in areas $3 b$ and 1 in adult owl and squirrel monkeys. Neuroscience 10:639-665.

Rao SB, Welker E, Dörff J, Melzer P, Van der Loos H (1989) Plasticity in the barrel cortex of the adult mouse: effects of prolonged whisker stimulation on acute stimulus evoked DG-uptake. Soc Neurosci Abstr 15:1222.

Rhoades RW, Belford GR, Killackey HP (1987) Receptive-field propcrtics of rat ventral postcrior medial ncurons before and after selective kainic acid lesions of the trigeminal brain stem complex. J Neurophysiol 57:1577-1600.

Schwartz WJ, Smith CB, Davidsen L, Savaki H, Sokoloff L, Mata M, Fink DJ, Gainer H (1979) Metabolic mapping of functional activity 
in the hypothalamo-neurohypophysial system of the rat. Science 205 723-725.

Simons DJ (1985) Temporal and spatial integration in the rat SI vibrissa cortex. J Neurophysiol 54:615-635.

Simons DJ, Carvell GE (1989) Thalamocortical response transformation in the rat vibrissa/barrel system. J Neurophysiol 61:311-330.

Sokoloff L, Reivich M, Kennedy C, Des Rosiers MH, Patlak CS, Pettigrew KD, Sakurada O, Shinohara M (1977) The $\left[{ }^{14} \mathrm{C}\right]$ deoxyglucose method for the measurement of local cerebral glucose utilization: theory, procedure and normal values in the conscious and anesthetized albino rat. J Neurochem 28:897-916.

Thompson RF, Spencer WA (1966) Habituation: a model phenomenon for the study of neuronal substrates of behavior. Psychol Rev 73:16-43.

Turnbull BG, Rasmusson DD (1990) Acute effects of total or partial digit denervation on raccoon somatosensory cortex. Somatosens Motor Res 7:365-389.

Van der Loos H, Welker E, Dörfl J, Rumo G (1986) Selective breeding for variations in patterns in mystacial vibrissae of mice. Bilaterally symmetrical strains derived from ICR stock. J Hered 77:66-82.

Wall JT, Cusick CG (1984) Cutaneous responsiveness in primary somatosensory (S-I) hindpaw cortex before and after partial hindpaw deafferentation in adult rats. J Neurosci 4:1499-1515.

Warren R, Tremblay N, Dykes RW (1989) Quantitative study of glutamic acid decarboxylase-immunoreactive neurons and cytochrome oxidase activity in normal and partially deafferented rat hindlimb somatosensory cortex. J Comp Neurol 288:583-592.

Webster WR, Servière J, Martin R, Brown M (1985) Uncrossed and crossed inhibition in the inferior colliculus of the cat: a combined 2-deoxyglucose and electrophysiological study. J Neurosci 5:18201832.

Welker E, Van der Loos H (1986) Quantitative correlation between barrelfield size and the sensory innervation of the whiskerpad: a comparative study in six strains of mice bred for different patterns of mystacial vibrissae. J Neurosci 6:3355-3373.
Welker E, Hoogland PV, Van der Loos H (1988) Organization of feedback and feedforward projections of the barrel cortex: a PHA-L study in mouse. Exp Brain Res 73:411-435.

Welker E, Soriano E, Van der Loos H (1989a) Plasticity in the barrel cortex of the adult mouse: effects of peripheral deprivation on GADimmunoreactivity. Exp Brain Res 74:441-452.

Welker E, Soriano E, Dörfl J, Van der Loos H (1989b) Plasticity in the barrel cortex of the adult mouse: transient increase of GADimmunoreactivity following sensory stimulation. Exp Brain Res 78: 659-664.

Welker E, Van der Loos H, Dörfl J, Soriano E (1990a) The possible role of GABAergic innervation in plasticity of adult cerebral cortex. In: The neocortex ontogeny and phylogeny (Finlay BL, Innocenti $\mathrm{G}$ Scheich H, eds), pp 237-243. New York: Plenum.

Welker E, Armstrong-James M, Van der Loos H (1990b) Physiological aspects of the barrel cortex of the mouse: a single unit laminar latency analysis. Soc Neurosci Abstr 16:1215.

White EL (1979) Thalamocortical synaptic relations: a review with emphasis on the projections of specific thalamic nuclei to the primary sensory areas of the neocortex. Brain Res Rev 1:275-311.

Wise SP, Jones EG (1976) The organization and postnatal development of the commissural projection of the rat somatic sensory cortex. J Comp Neurol 168:313-343.

Wise SP, Jones EG (1977) Cells of origin and terminal distribution of descending projections of the rat somatic sensory cortex. J Comp Neurol 175:129-157.

Wong-Riley M (1979) Changes in the visual system of monocularly sutured or enucleated cats demonstrable with cytochrome oxidase histochemistry. Brain Res 171:11-28.

Woolsey TA, Dierker ML, Wann DF (1975) Mouse Sml cortex: qualitative and quantitative classification of Golgi-impregnated barrel neurons. Proc Natl Acad Sci USA 72:2165-2169. 